\title{
State-of-the-art and limitations in the life cycle assessment of ionic liquids
}

\author{
Vinícius Gonçalves Maciel, ${ }^{1,2}$ Dominic J. Wales, $, 3,4{ }^{\dagger}$ Marcus Seferin, ${ }^{1,2}$ Cássia Maria Lie Ugaya, ${ }^{5}$ Victor \\ Sans* 3,4
${ }^{1}$ School of Chemistry, Pontifical Catholic University of Rio Grande do Sul, Porto Alegre, Brazil
${ }^{2}$ Polytechnic School, Post-Graduation Program in Materials Engineering and Technology, Pontifical Catholic University of Rio Grande do Sul, Porto Alegre, Brazil
${ }^{3}$ Faculty of Engineering, University of Nottingham, Nottingham, NG7 2RD, U.K.
${ }^{4}$ GSK Carbon Neutral Laboratory, University of Nottingham, Nottingham, NG7 2GA, U.K.
${ }^{5}$ Gyro Center of Life Cycle Sustainability Assessment, Federal University of Technology- Paraná, UTFPR, Brazil, CNPq fellow \\ * victor.sanssangorrin@nottingham.ac.uk
}

\begin{abstract}
Even though the development and use of ionic liquids (ILs) has rapidly grown in recent years in the literature, information addressing the environmental performance of these substances in a life cycle context is comparatively scarce. This review critiques the state-of-theart environmental life cycle assessment (LCA) studies on ILs in the literature, identifies the existing shortcomings, which could be delaying complete employment of the LCA framework to the field of ILs, and also identifies strategies for overcoming these shortcomings. This review indicates that there are several limitations associated with the implementation of the LCA in all steps and discusses them. Since data about manufacturing at industrial scale are generally inaccessible, a set of methods and assumptions have been used in previous studies to determine the life cycle inventories (LCIs), such as simplified LCA, "tree life-cycle approach", use of energy monitor devices, thermodynamic methods, chemical simulation process and other secondary data. However, the analysis of the data quality has not always been performed. Also, the shortage of the characterisation factors of ILs for human toxicity and ecotoxicity impact categories, prevents its inclusion within the life cycle impact assessment (LCIA) step. Therefore, sufficient and complete life cycle inventory data for ionic liquids and precursor chemicals are essential for inventory analysis; and the LCIA needs to be clearly defined about the level of detail on the IL emissions. Current LCA studies on ILs have not covered all these aspects. To
\end{abstract}

\footnotetext{
${ }^{\dagger}$ Present Affiliation: The Hamlyn Centre, Faculty of Engineering, South Kensington Campus, Imperial College London, London, SW7 2AZ, U.K.
} 
improve the present situation, it is proposed herein that for future LCA of processes involving ILs, each of the LCA steps must be completed as far as scientific advances allow.

Key words: life cycle inventory, chemical inventory, ionic liquids, life cycle assessment 


\section{INTRODUCTION}

Ionic liquids (ILs) are ionic compounds that feature intermolecular interactions between a cationic organic moiety and an inorganic or organic anion. Since 2000, the number of published papers concerning ionic liquids has rapidly grown (Figure 1). Indeed, the potential and benefits of ILs in various industrial applications have been recognized and highlighted extensively (Disasa Irge, 2016). An advantage of ILs is the capacity for adjusting the properties through appropriate choice of the cations and anions (D'Alessandro et al., 2010). Therefore, many different ILs have been reported because of the huge amount of possible combinations of anions and cations (Ghandi, 2014). Furthermore, these substances show advanced properties such as non-flammability, thermal stability, negligible vapour pressure and wide electrochemical windows (Ghandi, 2014; Wasserscheid and Welton, 2008). These unique and promising characteristics, in addition to the near-infinite combinations of anions and anions, mean that ILs are good candidates for a vast array of uses including, use as solvents (Ghandi, 2014; Kowsari, 2011; Zhang et al., 2012), in chemical synthesis (Plechkova and Seddon, 2008), in electrochemistry (Hagiwara and Lee, 2007), for carbon capture (Bernard et al., 2016; TorralbaCalleja et al., 2013), polymeric derived materials and devices (Karjalainen et al., 2018; Sans et al., 2011; Wales et al., 2018; Yuan et al., 2013) and many more. 


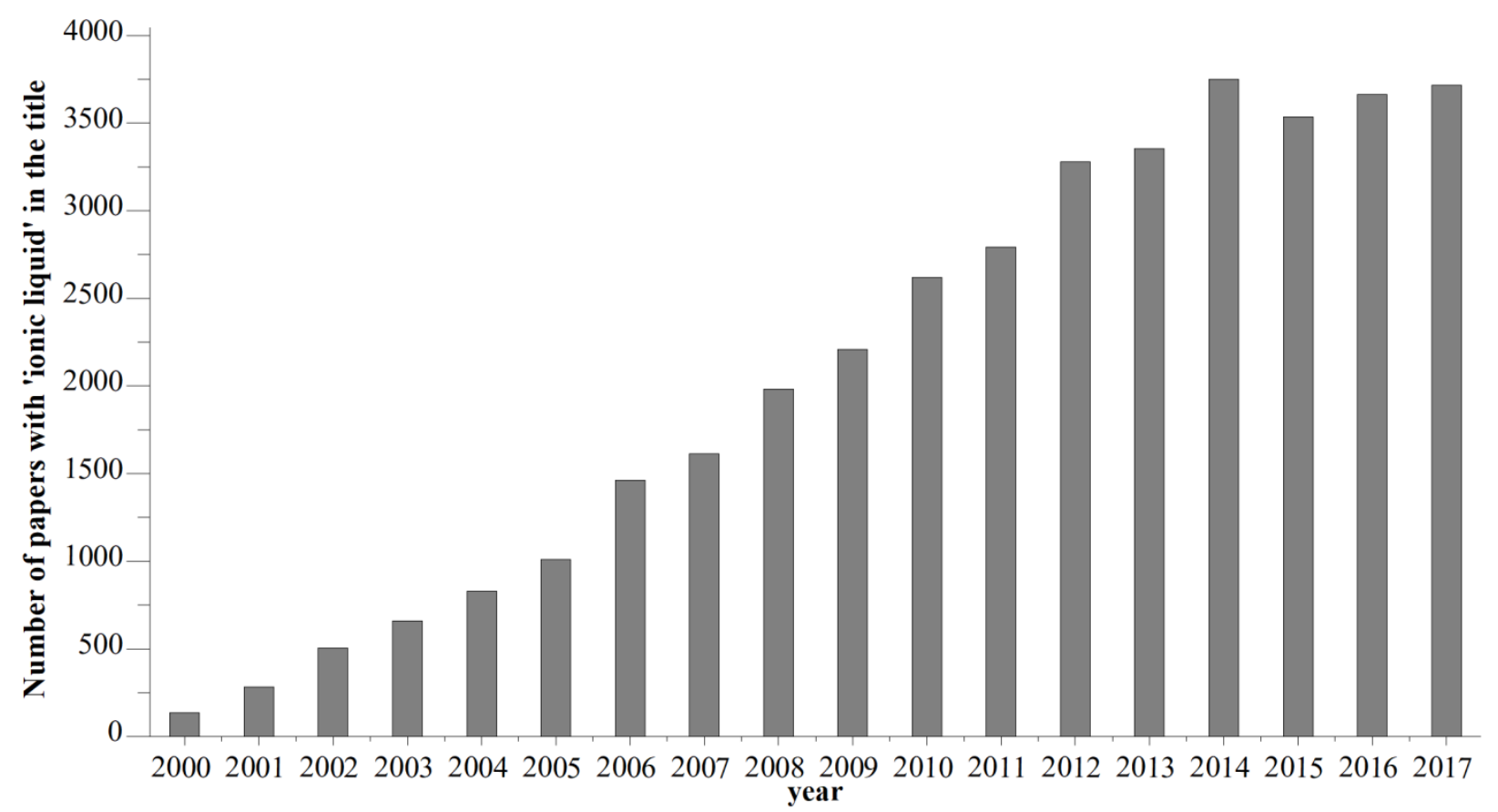

Figure 1. The number of published papers with the term 'ionic liquid' within the title has grown steadily since 2000. Data obtained by searching for number of publications each year with 'ionic liquid' within the title in the period of $2000-2017$ inclusive in the Web of Science ${ }^{\mathrm{TM}}$ database by Clarivate Analytics.

Over the past decade, it has been claimed that ILs are "green solvent" replacements for organic solvents due to negligible volatility (Disasa Irge, 2016; Zhu et al., 2009). However, a reduction in vapour emissions does not automatically make a greener process (Kralisch et al., 2005). Furthermore, in most cases, synthesis of ILs includes a series of reactions and purification steps using volatile organic solvents (Zhu et al., 2009). Compared to processes that use conventional organic solvents, it is highly likely that processes that use ILs as a solvent will have a larger lifecycle environmental impact (Zhang et al., 2008).

Concerns regarding to the impact of ILs on the environment and human health have been reported (Disasa Irge, 2016; Heckenbach et al., 2016). Many ILs present a comparatively high level of toxicity toward freshwater organisms, (Mehrkesh and Karunanithi, 2016a) and indeed, Pham et al. (2010) wrote an extensive review on IL toxicity to aquatic organisms. Furthermore, the limited number of ionic liquid toxicological studies published thus far indicate that the ionic liquids may have deleterious effects on human health (Mehrkesh and Karunanithi, 2016b; Zhu et al., 2009). 
Zhu et al.(2009) recommended that the environmental performance of the application of ILs ought to be assessed with the life cycle assessment (LCA) method, which considers the full process; raw material extraction, through the ionic liquids synthesis, to process applications, and to the recovery of ILs for reuse. Life cycle assessment (LCA) is an exhaustive framework that quantifies the environmental sustainability of a system, product or process over the complete life cycle (de Bruijn et al., 2002). Nowadays, LCA has become an essential part of decision-making in industrial, governmental and non-governmental organizations, (Kralisch et al., 2015) as well as being explored by the scientific community (Cerdas et al., 2017; Cuéllar-Franca et al., 2016; Jacquemin et al., 2012). The wide application of LCA is due to the credibility, scientific recognition and clear application guidance of the ISO 14040 standard (ISO 14040, 2006), and the ISO 14044 standard (ISO 14044, 2006).

However, there are very few LCA studies on processes that involve ILs, despite the huge growth in ionic liquid science and applications (see Figure 1) This is attributed to these compounds being recently emerging materials (Cuéllar-Franca et al., 2016) and because there are few inventory database available on the ILs and their precursors (Mehrkesh and Karunanithi, 2016a). Besides that, particular guidance for conducting a life cycle assessment for the case of ILs is absent. Thus, the core question which must be asked before utilization of the LCA framework to processes involving ionic liquids is whether there are sufficient and comprehensive Life Cycle Assessments (LCAs) for the ILs reported in the published literature.

The purpose of this perspective review is to give a critique of environmental life cycle assessment studies established on ionic liquids, to distinguish the existing shortcomings, which are delaying a complete utilization of the life cycle assessment framework to processes involving ILs, and designation of strategies to overcome the disadvantages. This review consists of six distinct parts. Firstly, section 3 covers a detailed review and analysis of existing LCA studies. Afterwards, the goal and scope of studies are investigated in section 4. Then the methods and strategies used to build life cycle inventory of ionic liquids are discussed in section 5, followed by an overview on the impact categories and methods applied (section 6). The interpretation step 
is addressed in section 7 and finally, a summary of the shortcomings that were identified, and the proposed strategies to overcome the shortcomings, is presented in section 8 . 


\section{METHODOLOGY}

A scientific literature search up until February 2018 was conducted using the following literature databases: Web of Science online database, Science Direct, and Google Scholar. The search was strategy followed a sequential search limited to "ionic liquid" and "life cycle" published in English, excluding commentaries, news articles, reviews and letters or opinion pieces.

In this review, for a better understanding of the current situation involving the use of LCA methodology for evaluation of ILs and IL processes, four criteria were applied for each LCA step. The description of criteria and an associated 'criteria weight' attributed to them are presented in Table 1. 
Table 1 Criteria for the analysis of studies applied in this review for each life cycle assessment steps.

\begin{tabular}{|c|c|c|c|c|}
\hline \multirow[t]{2}{*}{ Steps of LCA } & \multirow{2}{*}{$\begin{array}{l}\text { Description } \\
\text { of criteria }\end{array}$} & & Criteria weight & \\
\hline & & High & Medium & Low \\
\hline $\begin{array}{l}\text { Goal and } \\
\text { Scope }\end{array}$ & $\begin{array}{l}\text { Life Cycle } \\
\text { Stages } \\
\text { covered }\end{array}$ & $\begin{array}{l}\text { Cradle-to-grave, product } \\
\text { systems and system } \\
\text { boundaries } \\
\text { defined }\end{array}$ & $\begin{array}{l}\text { Cradle-to-gate or } \\
\text { product systems and } \\
\text { system boundaries } \\
\text { partially defined }\end{array}$ & $\begin{array}{l}\text { Gate-to-gate or product } \\
\text { systems or system } \\
\text { boundaries are not defined }\end{array}$ \\
\hline $\begin{array}{l}\text { Life Cycle } \\
\text { Inventory } \\
\text { analysis }\end{array}$ & $\begin{array}{l}\text { Clear } \\
\text { information } \\
\text { about the data } \\
\text { used }\end{array}$ & $\begin{array}{l}\text { Comprehensive data, } \\
\text { inclusive of information } \\
\text { on masses, energies and } \\
\text { by-products }\end{array}$ & $\begin{array}{l}\text { Incomplete data with } \\
\text { the gaps in the data } \\
\text { filled with qualified } \\
\text { assumptions }\end{array}$ & $\begin{array}{l}\text { Incomplete data with the } \\
\text { data gaps not filled }\end{array}$ \\
\hline $\begin{array}{l}\text { Life cycle } \\
\text { Impact } \\
\text { Assessment }\end{array}$ & $\begin{array}{l}\text { Impact } \\
\text { categories } \\
\text { covered }\end{array}$ & $\begin{array}{l}\text { Covered multiple impact } \\
\text { categories, also impact } \\
\text { categories and } \\
\text { characterization methods } \\
\text { are clearly defined and } \\
\text { justified }\end{array}$ & $\begin{array}{l}\text { Only one impact } \\
\text { category evaluated } \\
\text { and/or its choice and } \\
\text { characterization } \\
\text { methods partially } \\
\text { defined and/or } \\
\text { justified }\end{array}$ & $\begin{array}{l}\text { Impact categories and/or } \\
\text { characterization methods } \\
\text { not defined and justified }\end{array}$ \\
\hline Interpretation & Data quality & $\begin{array}{l}\text { Performed an analysis of } \\
\text { the data quality }\end{array}$ & $\begin{array}{l}\text { Analysis of the data } \\
\text { quality partially } \\
\text { performed }\end{array}$ & $\begin{array}{l}\text { Did not perform an analysis } \\
\text { of the data quality. }\end{array}$ \\
\hline
\end{tabular}

Goal and Scope: the stages of the life cycle covered (cradle-to-grave, gate-to-gate and cradle-togate) and product systems were chosen as parameters to evaluate the studies. The ISO 14044 standard states that the whole life cycle should be accounted for (cradle-to-grave) and only similar processes can be left out in LCA studies of comparison. Furthermore, product systems and system boundaries need to be clearly defined (de Bruijn et al., 2002). Besides that, the guideline of the World Business Council for Sustainable Development's Chemical Sector (WBCSD, 2014) recommended that system boundaries should be cradle-to-grave for chemical product footprint, and when the goal of the assessment is to provide environmental information at a business-to-business level (e.g. chemical industry products are intermediates and can be used in multiple applications), cradle-to-gate studies are acceptable. Thus, it was assumed that cradleto-grave or cradle-to-gate is a better approach than gate-to-gate. 
Life Cycle Inventory analysis: This step of the life cycle assessment in each published study was analyzed considering the completeness of data quality based on the indicator recommended by Kralisch et al. (2015). It is important to highlight that the purpose of this evaluation is to investigate if LCA studies were built from a comprehensive life cycle inventory studies. Hence, life cycle inventories that presented clear information about the data used, inclusive of data on masses, energies, by-products, and recycling were assumed as "high completeness".

Life cycle impact assessment step: LCA studies were awarded a 'high criteria weight' if more than one impact category was reported and if categories and characterization methods were justified. The selection of category indicators, impact categories and characterization models should be consistent and justified with respect to the goal and scope of the LCA, in agreement with the UNEP/SETAC Life Cycle Initiative (Margni et al., 2008).. Also, the WBCSD, (2014) recommended in their guidelines concerning assessment and reporting of product environmental footprints, that a decision tree for choosing impact categories should be included, if using the life cycle assessment approach. For instance, by applying this decision tree it implies that global warming potential and human toxicity potential must be included in chemical sector LCA studies.

Finally, in the interpretation step, LCA studies were analysed by considering if data quality analysis was performed within the study. ISO 14040 (ISO 14040, 2006) and ISO 14044 (ISO 14044, 2006) state that the data quality analysis is a compulsory part of the LCIA. 


\section{LIFE CYCLE ASSESSMENT STUDIES OF IONIC LIQUIDS}

In this literature search, eleven LCA studies on ionic liquids were found. Table 2 shows these eleven studies, the ionic liquids evaluated and a short introduction to each study. Generally speaking, the studies published to date have covered mainly butylmethylimidazolium $\left([\mathrm{Bmim}]^{+}\right)$ as the IL cation, as well as applications (e.g. as a solvent in reactions) of several of these $[\mathrm{Bmim}]^{+}$cation-based ILs.

Table 1.Life Cycle Assessment studies of Ionic liquids

\begin{tabular}{|c|c|c|c|}
\hline Entry & Reference & Description & ILs studied \\
\hline 1 & $\begin{array}{l}\text { Huebschmann et } \\
\text { al. (2011) }\end{array}$ & $\begin{array}{l}\text { Two case studies were shown: (i) a continuously running } \\
\text { phase transfer catalysis of phenyl benzoate without catalyst } \\
\text { and with ionic liquids as a catalyst; (ii) synthesis of the ionic } \\
\text { liquid [Bmim][Cl]. }\end{array}$ & $\begin{array}{l}{[\mathrm{Bmim}][\mathrm{Cl}]} \\
{\left[\mathrm{C}_{18} \mathrm{mim}\right][\mathrm{Br}]} \\
{[\mathrm{MIM}]\left[\mathrm{BuSO}_{3}\right]}\end{array}$ \\
\hline 2 & $\begin{array}{l}\text { Zhang et al., } \\
(2008)\end{array}$ & $\begin{array}{l}{[\mathrm{Bmim}]\left[\mathrm{BF}_{4}\right] \text { was the solvent and compared to conventional }} \\
\text { solvents for the synthesis of cyclohexane and for the Diels- } \\
\text { Alder reaction }\end{array}$ & {$[\mathrm{Bmim}]\left[\mathrm{BF}_{4}\right]$} \\
\hline 3 & $\begin{array}{l}\text { Kralisch et al., } \\
(2005)\end{array}$ & $\begin{array}{l}\text { LCA study of the synthesis of ionic liquid }[\mathrm{Bmim}]\left[\mathrm{BF}_{4}\right] \text { and } \\
\text { subsequent use of }[\mathrm{Bmim}]\left[\mathrm{BF}_{4}\right] \text { as a solvent in the } \\
\text { metathesis of 1-octene }\end{array}$ & {$[\mathrm{Bmim}]\left[\mathrm{BF}_{4}\right]$} \\
\hline 4 & $\begin{array}{l}\text { Kralisch et al., } \\
(2007)\end{array}$ & $\begin{array}{l}\text { Cost and environmental LCA of the }\left[\mathrm{C}_{6} \mathrm{MIM}\right][\mathrm{Cl}] \text { synthesis } \\
\text { and comparison to }\left[\mathrm{C}_{6} \mathrm{Py}\right][\mathrm{Cl}] \text {. }\end{array}$ & $\begin{array}{l}{\left[\mathrm{C}_{6} \mathrm{MIM}\right][\mathrm{Cl}] \text { and }} \\
{\left[\mathrm{C}_{6} \mathrm{Py}\right][\mathrm{Cl}]}\end{array}$ \\
\hline 5 & $\begin{array}{l}\text { Farahipour and } \\
\text { Karunanithi, } \\
\text { (2014) }\end{array}$ & $\begin{array}{l}\text { LCA study of carbon capture storage (CCS) using } \\
{[\text { Bmim] }] \text { Ac] as a solvent to } \mathrm{CO}_{2} \text { absorption and LCA }} \\
\text { comparison to the organic solvent. }\end{array}$ & {$[\mathrm{Bmim}][\mathrm{Ac}]$} \\
\hline 6 & $\begin{array}{l}\text { Cuéllar-Franca et } \\
\text { al., (2016) }\end{array}$ & $\begin{array}{l}\text { This study presents a discussion on the estimation of the life } \\
\text { cycle environmental impacts of ILs, and an application } \\
\text { employing trihexyltetradecylphosphonium 1,2,4-triazolide } \\
\left(\left[\mathrm{P}_{66614]}[124 \text { Triz] })\right.\right.\end{array}$ & {$\left[\mathrm{P}_{66614}\right][124$ Triz $]$} \\
\hline 7 & $\begin{array}{l}\text { Mehrkesh and } \\
\text { Karunanithi, } \\
\text { (2013) }\end{array}$ & $\begin{array}{l}\text { Comparative LCA focusing on the synthesis of an energetic } \\
\text { ionic liquid (1,2,3-triazolium nitrate) and 2,4,6-trinitrotoluene } \\
\text { (TNT), a traditional energetic material. }\end{array}$ & $\begin{array}{l}\text { 1,2,3-triazolium } \\
\text { nitrate }\end{array}$ \\
\hline 8 & $\begin{array}{l}\text { Mehrkesh and } \\
\text { Karunanithi, } \\
\text { (2016a) }\end{array}$ & $\begin{array}{l}\text { The study compared the aquatic ecotoxicity impacts resulting } \\
\text { from the production and application phase } \\
\text { of five ionic liquids. }\end{array}$ & $\begin{array}{l}{[\mathrm{Bmim}]\left[\mathrm{BF}_{4}\right],} \\
{[\mathrm{Bmim}][\mathrm{Br}],} \\
{[\mathrm{Bmim}][\mathrm{Cl}],} \\
{[\mathrm{Bmim}]\left[\mathrm{PF}_{6}\right] \text { and }} \\
{[\mathrm{BPy}][\mathrm{Cl}]}\end{array}$ \\
\hline 9 & $\begin{array}{l}\text { Righi et al., } \\
\text { (2011) }\end{array}$ & $\begin{array}{l}\text { The authors performed a "cradle to gate" LCA to analyse the } \\
\text { environmental impacts of the dissolution of cellulose in the } \\
\text { ionic liquid 1-butyl-3-methylimidazolium chloride } \\
\text { ([Bmim][Cl]) }\end{array}$ & {$[\mathrm{Bmim}][\mathrm{Cl}]$} \\
\hline 10 & Peterson, (2013) & $\begin{array}{l}\mathrm{LCA} \text { of ionic liquids applied as a co-fluid of } \mathrm{CO}_{2} \text { in a } \\
\text { refrigeration system }\end{array}$ & $\begin{array}{l}{[\mathrm{Hmim}]\left[\mathrm{NTf}_{2}\right],} \\
{\left[\mathrm{P}_{66614}\right][3 \text { triazolide }]}\end{array}$ \\
\hline 11 & $\begin{array}{l}\text { Amado Alviz and } \\
\text { Alvarez, (2017) }\end{array}$ & $\begin{array}{l}\text { The environmental impact of }[\mathrm{Bmim}][\mathrm{Br}] \text { ionic liquid was } \\
\text { compared to that of toluene when used in the synthesis of } \\
\text { acetylsalicylic acid. }\end{array}$ & $\begin{array}{l}{[\mathrm{Bmim}][\mathrm{Br}],} \\
{[\mathrm{Bmim}][\mathrm{Cl}]}\end{array}$ \\
\hline
\end{tabular}


One of the first studies that used LCA to evaluate ILs was by Kralisch et al. (2005). They studied the employment of ILs as solvent for the metathesis of 1-octene compared to conventional solvents. Furthermore, they analyzed the energy requirement, environmental impact and substrate costs for the synthesis of 1-butyl-3-methylimidazolium tetrafluoroborate $\left([\mathrm{Bmim}]\left[\mathrm{BF}_{4}\right]\right)$. Their results demonstrated that in certain circumstances, a reaction which is solvent-free may not necessarily be advantageous ecologically. In addition, the study questioned the assumption that a biphasic reaction is superior to a homogeneous phase reaction due to facilitated recycling. This was done by comparison of the energy requirement for the synthesis of a solvent which enables biphasic operation (e.g. ionic liquid) to the energy required to separate an homogeneous reaction mixture by distillation. The results showed a small difference between both processes.

Over the last ten years, several studies have assessed the use of ILs as a solvent to improve chemical processes. For example, an LCA study that compared the use of different solvents, such as organic solvents (acetone, benzene, ethyl ether), water and the ionic liquid $\left[\mathrm{Bmim}^{-}\left[\mathrm{BF}_{4}\right]\right.$, for the synthesis of cyclohexane and also for a Diels-Alder reaction (Zhang et al., (2008)). The results indicated that for processes that use ILs it is highly likely that there will be a bigger life cycle environmental impact than for processes that use the other solvents analyzed. One recent study used LCA analysis to evaluate, during the synthesis of a pharmaceutical product, the employment of an IL as solvent. compared to the use of toluene. The results of comparing the environmental profile of the ionic liquid $[\mathrm{Bmim}][\mathrm{Br}]$ to that of toluene in the synthesis of aspirin (acetylsalicylic acid) indicated that the IL had larger environmental impacts than the organic solvent, particularly in the ecotoxicity impact categories (Alviz and Alvarez, (2017)). Also, the effect of solvent recovery using separation technologies, and the effect of replacement of the anion $\left(\mathrm{Br}^{-}\right.$to $\left.\mathrm{Cl}^{-}\right)$of the ionic liquid were studied. Here, the environmental profile of $[\mathrm{Bmim}][\mathrm{Cl}]$ and $[\mathrm{Bmim}][\mathrm{Br}]$ were similar, although the toxicity of the former is comparatively higher.

There has been much interest paid to the use of ILs as potential candidates for carbon capture (Zhang et al., 2012). Cuéllar-Franca et al., (2016) recommended the use of LCA for evaluation of the environmental performance of ILs used for $\mathrm{CO}_{2}$ capture. The example of [P66614][124Triz] 
was employed to demonstrate the use of the life cycle methodology through estimation of the life cycle environmental impacts of the ionic liquid in comparison to monoethanolamine (MEA).

An LCA comparison between 1-butyl-3-methylimidazolium acetate ([Bmim][Ac]) and MEA for carbon capture and sequestration (CCS) processes was made by Farahipour and Karunanithi (2014). The study did not consider the synthesis of the IL, but it was considered a full LCA. Energy and mass flows were estimated from pilot plant results and chemical simulation processes. The results indicated that a CCS process, using the ionic liquid [Bmim][Ac], with 90\% $\mathrm{CO}_{2}$ capture efficiency reduced life cycle greenhouse gas (GHG) emissions by only $50 \%$. Peterson, (2013) conducted a full LCA, meaning a cradle-to-grave analysis of the synthesis of the ionic liquids 1-hexyl-3-methylimidazolium bis(trifluoromethylsulfonyl)imide and trihexyl(tetradecyl)phosphonium 1,2,3-triazolide and their use as a co-fluid involving $\mathrm{CO}_{2}$ in refrigerant systems. This author reported that ionic liquid synthesis did not cause a significant contribution to the environmental impacts assessed.

The use of the ionic liquid $[\mathrm{Bmim}][\mathrm{Cl}]$ to dissolve cellulose was compared to the environmental performance of the dissolution process currently used at an industrial scale with LCA analyses (Righi et al., (2011)). Their results suggest that the process with IL could be significant from an in terms of impact on the environment, since the impacts of the process are similar to the impacts of the method developed by McCorsley, (1981) which uses a mixture of water and Nmethylmorpholine $\mathrm{N}$-oxide $\left(\mathrm{NMMO} / \mathrm{H}_{2} \mathrm{O}\right)$. However, it was shown that the process that used $[\mathrm{Bmim}][\mathrm{Cl}]$ generated a higher environmental load in terms of abiotic resource depletion, ecotoxicity and volatile organic compound emissions than the mixed $\mathrm{NMMO} / \mathrm{H}_{2} \mathrm{O}$ solvent system.

An advantage of ionic liquids is the ability to diversify the properties through appropriate choice of the anion and cation and (D'Alessandro et al., 2010). Kralisch et al., (2007) compared the effect of the exchange of the N-base cation (where -base is either methylimidazole or pyridine). In this study, the configuration of optimized parameters for the synthesis of 1-hexyl-3methylimidazolium chloride $\left(\left[\mathrm{C}_{6} \mathrm{mim}\right][\mathrm{Cl}]\right)$ was chosen as the starting configuration for the synthesis of n-hexylpyridinium chloride $\left(\left[\mathrm{C}_{6} \mathrm{Py}\right] \mathrm{Cl}\right)$. 
Huebschmann et al., (2011) have presented their research of a simplified life cycle assessment (SLCA), which is complemented with a superficial cost analysis that is exemplified with a pair of case studies: continuous running phase transfer catalysis of phenol and benzoyl chloride producing phenyl benzoate, and the solventless synthesis of $[\mathrm{Bmim}][\mathrm{Cl}]$. Ionic liquids $\left([\mathrm{Bmim}][\mathrm{Cl}],[\mathrm{mim}]\left[\mathrm{BuSO}_{3}\right]\right.$ and $\left.\left[\mathrm{C}_{18} \mathrm{mim}\right][\mathrm{Br}]\right)$ were used in catalytic amounts, as opposed to being used as solvents. Nevertheless, from an ecological viewpoint, [mim] $\left[\mathrm{BuSO}_{3}\right]$ was found to be more beneficial than $\left[\mathrm{C}_{18} \mathrm{mim}\right][\mathrm{Br}]$, due to the exothermic synthesis, whereas the latter is synthesized in an endothermic reaction, which requires $48 \mathrm{~h}$ of heating to $90{ }^{\circ} \mathrm{C}$. However, for the batch synthesis, the use of $[\mathrm{Bmim}][\mathrm{Cl}]$ had the lowest overall environmental impacts. Also, the results are contrary to the cumulative energy demand (CED) of the batch syntheses, which indicates, that under similar conditions (i.e. with an identical energy demand for controlling and pumping) the continuously running synthesis would have a threefold ecological benefit.

Mehrkesh and Karunanithi, (2013) reported a cradle-to-gate life cycle environmental impacts for the synthesis of the ionic liquid 1,2,3-triazolium nitrate and compared it to the synthesis of 2,4,6trinitrotoluene (TNT). It was found that synthesis of the IL has a significant larger environmental impact than the production process for TNT. 


\section{GOAL AND SCOPE OF LCA STUDIES}

The step which involves defining the goal and scope of the LCA is the phase in which the first decisions concerning the working plan of the entire LCA are formed. The goal should be formulated with respect to the exact question, intended application and target audience (de Bruijn et al., 2002). The scope of the study should be performed related to technological, geographical and temporal coverage, and the degree of sophistication relative to the goal (ISO 14040 (ISO 14040, 2006)). Also, the product or process assessed must be defined relative to the function and functional unit (de Bruijn et al., 2002), and that all the inputs and outputs are assigned to the functional unit (Kralisch et al., 2015). ILs feature many specific functions and material properties (Ghandi, 2014; Wasserscheid and Welton, 2008). Therefore, the functional unit (FU) defines the main function or functions fulfilled by a product system and also specifies the extent of the function that will be examined in the resultant LCA study (de Bruijn et al., 2002). For instance, for a synthesis, the functional unit could be defined in terms of the product synthesized.

In general, the goal and scope of the studies assessed in this work focused on the use of ionic liquids as a substitute for traditional organic solvents in chemical reactions. Table $\mathbf{3}$ shows the scope of the LCA studies of ILs in the literature, the functional unit assumed and the IL applications described.

Table 2. The scope of LCA studies, functional unit and applications of IL

\begin{tabular}{|c|c|c|c|c|}
\hline Entry & Reference & Applications & System boundaries & Functional Unit \\
\hline 1 & Huebschmann et al. (2011) & Catalyst & Cradle-to-Gate & $1 \mathrm{~kg}$ of phenyl benzoate \\
\hline 2 & Zhang et al., (2008) & Solvent & Cradle-to-Gate & $1 \mathrm{~kg}$ of the solvent \\
\hline 3 & Kralisch et al., (2005) & Solvent & Cradle-to-Gate & $\mathrm{n} / \mathrm{a}$ \\
\hline 4 & Kralisch et al., (2007) & $\mathrm{n} / \mathrm{a}$ & $\mathrm{n} / \mathrm{a}$ & $\mathrm{n} / \mathrm{a}$ \\
\hline 5 & $\begin{array}{l}\text { Farahipour and Karunanithi, } \\
\text { (2014) }\end{array}$ & Solvent & Cradle-to-Gate & $1 \mathrm{MWh}$ \\
\hline 6 & Cuéllar-Franca et al., (2016) & $\mathrm{n} / \mathrm{a}$ & Cradle-to-Gate & $1 \mathrm{~kg}$ of $\left[\mathrm{P}_{66614}\right][124$ Triz] \\
\hline 7 & $\begin{array}{l}\text { Mehrkesh and Karunanithi, } \\
\text { (2013) }\end{array}$ & Energetic ionic salt & Cradle-to-Gate & $1 \mathrm{MJ}$ energy content \\
\hline 8 & $\begin{array}{l}\text { Mehrkesh and Karunanithi, } \\
\text { (2016a) }\end{array}$ & $\mathrm{n} / \mathrm{a}$ & Cradle-to-Gate & $1 \mathrm{~kg}$ of IL \\
\hline 9 & Righi et al., (2011) & Cellulose dissolution & Cradle-to-Gate & $\begin{array}{l}1 \mathrm{~kg} \text { of the dissolved } \\
\text { cellulose }\end{array}$ \\
\hline 10 & Peterson, (2013) & $\begin{array}{l}\text { As a co-fluid of } \mathrm{CO}_{2} \text { in a } \\
\text { refrigeration system }\end{array}$ & Cradle-to-Grave & $\mathrm{n} / \mathrm{a}$ \\
\hline 11 & $\begin{array}{l}\text { Amado Alviz and Alvarez, } \\
\text { (2017) }\end{array}$ & Solvent & Cradle-to-Gate & $1 \mathrm{~kg}$ of acetylsalicylic acid \\
\hline
\end{tabular}

n/a: not available 
Defining the system boundaries is a very crucial part of the scope definition in the life cycle assessment. Both the system boundaries and the product systems need to be clearly defined in each step of the life cycle, inclusive of inputs, processing routes, temporal and spatial considerations (de Bruijn et al., 2002). Furthermore, it is recommended that the system boundaries are justified towards the goal of the study (de Bruijn et al., 2002). However, some studies reviewed here did not show clearly defined system boundaries (see Table 3). The product system describes which of the processes that constitute the whole life cycle are to be within the assessment. In the most complete and inclusive LCA, the system boundaries should include the acquisition of raw materials, the production, use, treatment at end-of-life, recycling and final disposal (i.e. cradle-to-grave). However, simplifications may be made as long as they are systematic, justified and intentional, as opposed to inherently unconscious and implicit(de Bruijn et al., 2002). For instance, Cuéllar-Franca et al.(2016) reported a study considering the environmental impacts from extraction of raw materials until the 'laboratory gate'. Hence, the application (use phase) and the final disposal of the ILs were neglected. This scope, in LCA terms, is termed a cradle-to-gate boundary (Figure 2). For studies of comparison, the most facile simplification is omission of life cycle stages that are the same for all products of comparison (de Bruijn et al., (2002); ISO 14044 (ISO 14044, 2006)). However, due to the unique characteristics of ILs the processes downstream (gate-to-grave), are often included within the system boundaries for comparative assessment of the use of ILs (Amado Alviz and Alvarez, 2017; Righi et al., 2011).

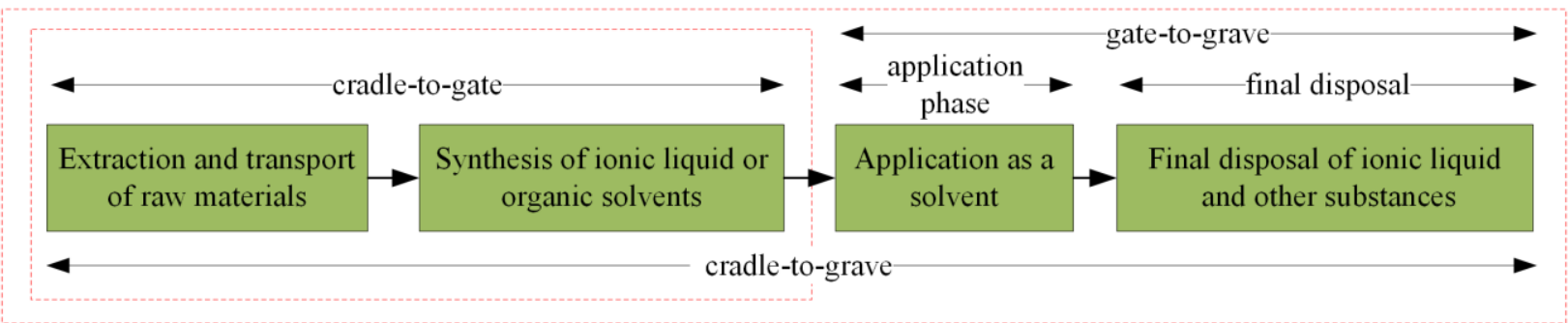

Figure 2. Scheme with a comparison of system boundaries between a conventional solvent and a IL used as a solvent in synthesis processes. 
Table 3. Results of criteria applied in this study for goal and scope step

\begin{tabular}{|c|c|c|c|}
\hline Entry & Study & Result & Justification \\
\hline 1 & Huebschmann et al. (2011) & Medium & $\begin{array}{l}\text { Product systems and system boundaries were partially } \\
\text { defined }\end{array}$ \\
\hline 2 & Zhang et al., (2008) & Medium & Cradle-to-gate approach \\
\hline 3 & Kralisch et al., (2005) & Medium & $\begin{array}{l}\text { Product systems and system boundaries were partially } \\
\text { defined }\end{array}$ \\
\hline 4 & Kralisch et al., (2007) & Low & Product systems and system boundaries were not defined \\
\hline 5 & Farahipour and Karunanithi, (2014) & Medium & Cradle-to-gate approach \\
\hline 6 & Cuéllar-Franca et al., (2016) & Medium & Cradle-to-gate approach \\
\hline 7 & Mehrkesh and Karunanithi, (2013) & Medium & Cradle-to-gate approach \\
\hline 8 & $\begin{array}{l}\text { Mehrkesh and Karunanithi, } \\
\text { (2016a) }\end{array}$ & Medium & Cradle-to-gate approach \\
\hline 9 & Righi et al., (2011) & Medium & Cradle-to-gate approach \\
\hline 10 & Peterson, (2013) & High & Cradle-to-grave approach \\
\hline 11 & Amado Alviz and Alvarez, (2017) & Medium & Cradle-to-gate approach \\
\hline
\end{tabular}

Notes: Criteria weight scale: Low = gate-to-gate or product systems or system boundaries are not defined. Medium = cradle-to-gate or system boundaries and product systems are partially defined. High $=$ cradle-to-grave and system boundaries and product systems are clearly defined.

\section{LIFE CYCLE INVENTORY ANALYSIS}

For the Life Cycle Inventory (LCI) large amount of data are required, to enable identification and quantification of the inputs and outputs of the studied system. Recently, various databases that provide transparent, relevant, accessible and reliable data for the creation of inventories have been developed (de Bruijn et al., 2002).

The importance of adequate and available LCI data is well known (Hischier and Walser, 2012). ILs are a relatively newly researched class of compounds and therefore there is not much primary data from industrial scale production available (Mehrkesh and Karunanithi, 2013). Furthermore, these substances can be synthesized from many precursors (Disasa Irge, 2016) that are not always available in inventory database. Thus, different methods have been utilized to 'plug' the data gaps, including known stoichiometric data, primary data from laboratory scale, thermodynamic methods, empirical scale-up and other relevant relationships. Table 4 shows a description of the main strategies applied to build the LCIs in the previously highlighted IL LCA studies in the literature. 
Table 4. Main strategies applied for building the life cycle inventories

\begin{tabular}{|c|c|c|c|c|c|c|c|c|}
\hline 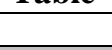 & 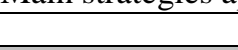 & \multicolumn{3}{|c|}{ Material balance } & \multicolumn{4}{|c|}{$\begin{array}{l}\text { Energy balance } \\
\end{array}$} \\
\hline Entry & Study & $\begin{array}{l}\text { Data from } \\
\text { laboratory } \\
\text { scale }\end{array}$ & $\begin{array}{c}\text { Data } \\
\text { from } \\
\text { literature }\end{array}$ & $\begin{array}{l}\text { Chemical } \\
\text { simulation } \\
\text { software }\end{array}$ & $\begin{array}{l}\text { Calculated } \\
\text { from } \\
\text { thermo- } \\
\text { dynamic } \\
\text { models }\end{array}$ & Measurements & $\begin{array}{l}\text { Energy } \\
\text { data from } \\
\text { literature }\end{array}$ & $\begin{array}{l}\text { Chemical } \\
\text { simulation } \\
\text { software }\end{array}$ \\
\hline 1 & $\begin{array}{l}\text { Huebschmann } \\
\text { et al. (2011) }\end{array}$ & $\mathrm{X}$ & & & $\mathrm{X}$ & & & \\
\hline 2 & $\begin{array}{l}\text { Zhang et al., } \\
(2008)\end{array}$ & $\bar{X}$ & & & & & $\bar{X}$ & $\mathrm{X}$ \\
\hline 3 & $\begin{array}{l}\text { Kralisch et al., } \\
(2005)\end{array}$ & $\mathrm{X}$ & & & & $\mathrm{X}$ & & \\
\hline 4 & $\begin{array}{l}\text { Kralisch et al., } \\
(2007)\end{array}$ & $\mathrm{X}$ & & & & $\mathrm{X}$ & & \\
\hline 5 & $\begin{array}{l}\text { Farahipour and } \\
\text { Karunanithi, } \\
\text { (2014) }\end{array}$ & & $\mathrm{X}$ & $\mathrm{X}$ & & & $\bar{X}$ & $\mathrm{X}$ \\
\hline 6 & $\begin{array}{l}\text { Cuéllar-Franca } \\
\text { et al., (2016) }\end{array}$ & $\bar{X}$ & & & $\bar{X}$ & & & \\
\hline 7 & $\begin{array}{l}\text { Mehrkesh and } \\
\text { Karunanithi, } \\
\text { (2013) }\end{array}$ & & $\mathrm{X}$ & & $\mathrm{X}$ & & & \\
\hline 8 & $\begin{array}{l}\text { Mehrkesh and } \\
\text { Karunanithi, } \\
\text { (2016a) }\end{array}$ & & $\bar{X}$ & $\bar{X}$ & & & & $\bar{X}$ \\
\hline 9 & $\begin{array}{l}\text { Righi et al., } \\
\text { (2011) }\end{array}$ & & $\mathrm{X}$ & $\mathrm{X}$ & & & & $\mathrm{X}$ \\
\hline 10 & Peterson, (2013) & & $\mathrm{X}$ & $\mathrm{X}$ & & & & $\mathrm{X}$ \\
\hline 11 & $\begin{array}{l}\text { Amado Alviz } \\
\text { and Alvarez, } \\
(2017)\end{array}$ & & $\mathrm{X}$ & & & & $\mathrm{X}$ & \\
\hline
\end{tabular}

A life cycle assessment can be conducted with varying levels of sophistication; the ISO standard guidelines differentiate between the baseline detailed level, a simplified level, and any feasible expansions of the detailed level (ISO 14040, 2006; ISO 14044, 2006). However, it is necessary to rationalize and state the appropriate and required level of sophistication relative to the study goal and the specific decision situation (de Bruijn et al., 2002).

\subsection{Material balance}

The approaches employed by other researchers to build the material balance of processes involving ILs can be divided into three different methods; simplified life cycle approach 
(SLCA), life cycle tree approach and chemical simulation processes. Figure 3 highlights these three approaches and the works in which they have been utilized.

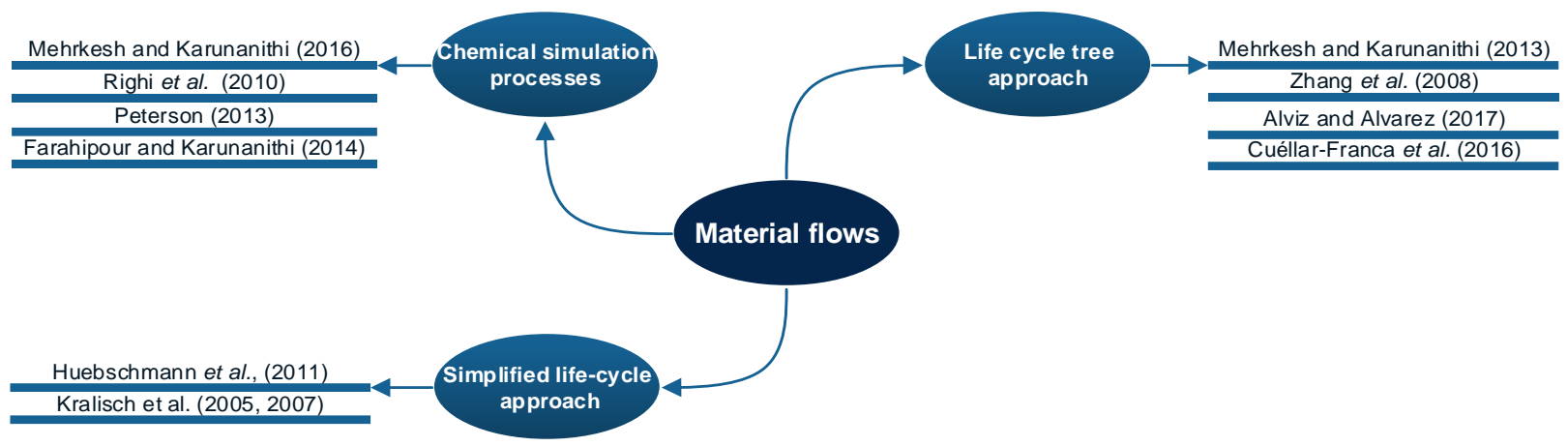

Figure 3. Main approaches used for determining material flows

Kralisch et al. (2005) were one of the first groups that reported an SLCA where upstream process and some inputs were neglected. Later, other studies also employed SLCA (Huebschmann et al., 2011; Kralisch et al., 2007, 2005). Overall, in this approach the main data employed were laboratory scale data and some life cycle phases were neglected, mainly the upstream phases (de Bruijn et al., 2002). The authors justified the SLCA approach due to the complexity, time spent and effort needed for conducting a full LCA study, mainly because of a scarcity of information concerning the background processes. In these processes the decisionmaker may apply none or indirect influence for which a life cycle assessment is carried out (Frischknecht, 1998). However, other LCA studies on ILs reported the biggest contribution impacts from background processes (Amado Alviz and Alvarez, 2017; Cuéllar-Franca et al., 2016; Righi et al., 2011). For example, in Alviz and Alvarez, (2017) the highest contributor to the impact categories evaluated in the $[\mathrm{Bmim}][\mathrm{Br}]$ life cycle were the background processes, namely the production of hydrogen bromide ( $\mathrm{HBr}), n$-butanol, methylamine and glyoxal. Thus, the synthesis of precursor substances present in the synthetic route of ionic liquids should not be neglected.

Recently, studies have employed the method known as the "life cycle tree approach" (CuéllarFranca et al., 2016; Mehrkesh and Karunanithi, 2013). In this approach, a life cycle tree of the ionic liquid to be studied is built, going back to the basic precursor substances for which available life cycle data can be accessed and used (e.g. hydrogen $\left(\mathrm{H}_{2}\right)$, ammonia $\left(\mathrm{NH}_{3}\right)$, benzene 
$\left(\mathrm{C}_{6} \mathrm{H}_{6}\right)$, methanol $\left(\mathrm{CH}_{3} \mathrm{OH}\right)$, etc. $)$. The main characteristic of that method is that it starts from the 'gate' or 'grave', and goes through all the main processes until the 'cradle'. Different to the SLCA, the life cycle tree approach can be considered a full life-cycle. However, this allencompassing approach is exceptionally time-consuming and an exhaustive step-by-step evaluation is necessary. This method is suitable for newly emergent chemical substances, like ILs, which have complex structures and involve various precursors where life cycle data are either scarce or unavailable (Cuéllar-Franca et al., 2016). In Figure 4, an example of a life cycle tree for $[\mathrm{Bmim}]\left[\mathrm{NTf}_{2}\right]$, based on routes of syntheses reported by Dunn et al., (2012) for [Bmim][NTf 2 , Righi et al., (2011) for [Bmim][Cl], Perterson, (2013) for lithium bis(trifluoromethane)sulfonamide $\left(\operatorname{LiNTf}_{2}\right)$, and available life cycle databases in Ecoinvent v 3.0 database software is highlighted. For this example, the LCIs of [Bmim][Cl], N-methylimidazole, 1-chlorobutane and $[\mathrm{Bmim}][\mathrm{Cl}]$ are not available in the ecoinvent database, and thus needed to be built. In the case of the life cycle tree for $\operatorname{LiNTf}_{2}$, the LCIs of methanesulfonyl chloride, methanesulfonyl fluoride, trifluoromethanesulfonyl fluoride, lithium nitride and $\mathrm{LiNTf}_{2}$ are not available in the ecoinvent database. In general, in this approach, the required raw materials for each precursor are estimated using the chemical reaction stoichiometric relationships (CuéllarFranca et al., 2016). However, limitations of this approach are the choice of synthetic route and the source of data used for building the life cycle inventory for each substance. 


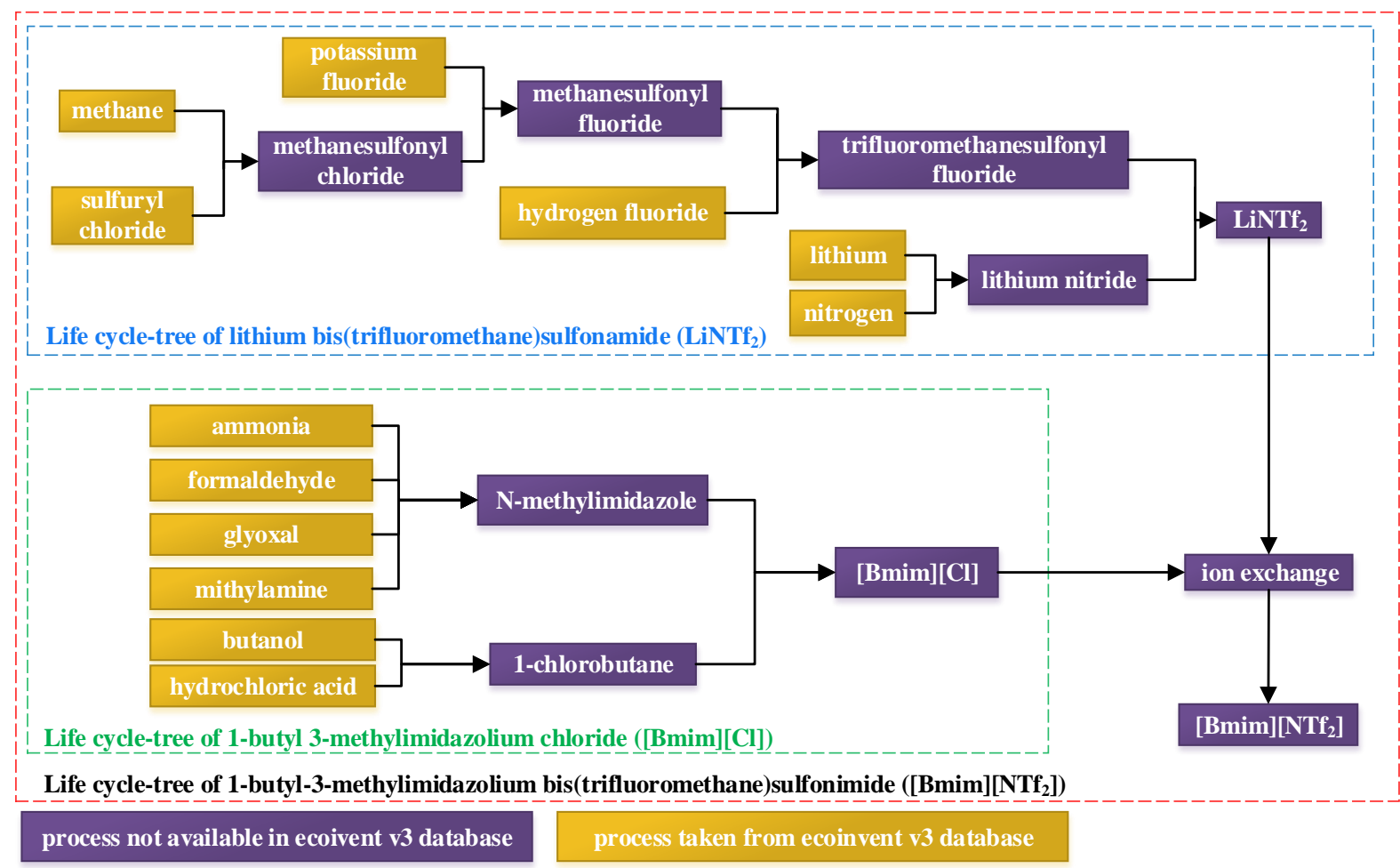

Figure 4. Example of life cycle tree for 1-butyl-3-methylimidazolium bis(trifluoromethane)sulfonimide [Bmim] $\left[\mathrm{NTf}_{2}\right]$. Considering routes of syntheses reported by Dunn et al., (2012) for [Bmim][NTf $\mathrm{NT}_{2}$, Righi et al., (2011) for [Bmim][Cl], Perterson, (2013) for LiNTf $_{2}$ and available life cycle databases in ecoinvent $v 3.0$ database software.

Very recently, Alviz and Alvarez (2017) published an LCA study on the production of acetyl salicylic acid from the 'cradle' to 'gate' in the pharmaceutical, which included the synthesis of acetic anhydride, salicylic acid, and the solvents ([Bmim] $[\mathrm{Br}]$ or toluene), and the entirety of the production chain precursors. However, even though in this work by Alviz and Alvarez did not explicitly report the use of life-cycle tree approach, all the precursors were considered from cradle-to-gate. Therefore, it can be considered that a life cycle tree approach was made.

The other approach to estimate the material balance is the use of chemical simulation processes. This approach is advantageous as it is feasible to simulate and predict both material and energy flows. However, in the case of ILs, the use of process design and simulation software for modelling production processes of the ionic liquids is sometimes not possible because of a scarcity of complete thermodynamic and physical property models for those substances and associated precursors (Mehrkesh and Karunanithi, 2013). 


\subsection{Energy balance}

The energy consumption has also been reported as an important source of impacts during the life cycle of ILs. For instance, it has been determined that $17 \%$ of ecotoxicity impacts were from consumption of energy in the IL life cycle (Mehrkesh and Karunanithi, 2016a). With regard to energy flows, different approaches have been used to calculate the energy demands of both the synthesis and usage of ionic liquids. The methods used in the literature to estimate the energy balance are divided into four approaches (Figure 5): use of an energy monitoring socket, energy balance (heat of reaction), chemical simulation processes and secondary data.

Kralisch et al., (2007, 2005) determined the energy demand for heating, stirring and other steps (use of a vacuum pump, water bath heating and condensation) by using an energy monitoring socket. Additionally, the cumulative of energy demand (CED) was considered from secondary data; the CEDs for chemicals not listed in inventories were determined experimentally by measuring the energy needed for certain processes or synthesis steps. When this was not achievable, the CEDs for compounds with a high degree of structural similarity, which were present in the database, were used.

The use of some assumptions and methods has been performed to estimate the energy consumption, since industrial scale manufacturing data were not available, and it was expected to be more intensive in terms of energy requirements than the theoretical energy requirements. In the work of Huebschmann et al., (2011) the mass flows of reactions were determined at the laboratory scale, and the amount of energy consumed as a result of the reactions (syntheses) was estimated based on energy balance (heat of reaction). Also, a heat transfer efficiency of $40 \%$ (in laboratory-based experiments) was assumed. On the other hand, the energy consumed by auxiliary equipment for the case of the continuously-flow syntheses, e.g. control systems and pumps, was obtained from measurements.

Mehrkesh and Karunanithi (2013) suggested that the estimation of energy flows could be achieved by using theoretical energy values and, later, used empirical factors for scale-up of chemical processes (Equation 1-3). For exothermic reactions, the authors suggested that 
electricity usage is 3.2 times higher than the theoretical consumption of electricity. In the case of endothermic reactions, heated through combustion of natural gas, it was assumed that the energy usage is 4.2 times higher than theoretically required. Furthermore, it was assumed that natural gas was used for heating of endothermic reactions and electricity was used for the cooling of exothermic reactions. Later, Cuéllar-Franca et al., (2016) reported using this method to calculate the theoretical energy usage during the synthesis of the ionic liquid [P66614][124Triz] and precursors, and they recommended it as an approach to calculate the energetic scale-up gaps for ILs. The method used by Cuéllar-Franca et al. consisted of calculating the heat of reaction based on the work of Felder and Rousseau, (2005) (Equation 2 and 3), and then these values were multiplied by the factors stated above (Mehrkesh and Karunanithi, 2013). However, one of the difficulties in applying this method is that in order to determine the heat of reaction $(\Delta \mathrm{H})$ it is necessary to know the heat capacities and heats of formation of the ionic liquid and intermediate substances/precursors (Felder and Rousseau, 2005). Cuéllar-Franca et al., (2016) reported the use of thermodynamic databases and use of data from substances with similar structure. However, there is also a method put forward by Valderrama et al., (2009) that allows for prediction of the heat capacities $(\mathrm{Cp})$ of ionic liquids. This method uses the group contribution approach to find values for the heat capacity of ionic liquids. Other methods for estimation of the heats of formation $\left(\Delta \widehat{\mathrm{H}}^{\circ}\right)$ have been reported in the literature, such as experimental methods (Dong et al., 2013; Zhu et al., 2012) and estimation through the use of genetic algorithm-based multivariate linear regression methods (Peterson, 2013; Vatani et al., 2007). Furthermore, in the literature, authors have reported the use of thermodynamics databases (ATcT (Active Thermochemical Tables), n.d.; DETHERM, 2017; NIST, 2017) to obtain heats of formation, or with the assumption that the required heat of formation is equivalent to that of a similar structure that can be determined (Cuéllar-Franca et al., 2016). 


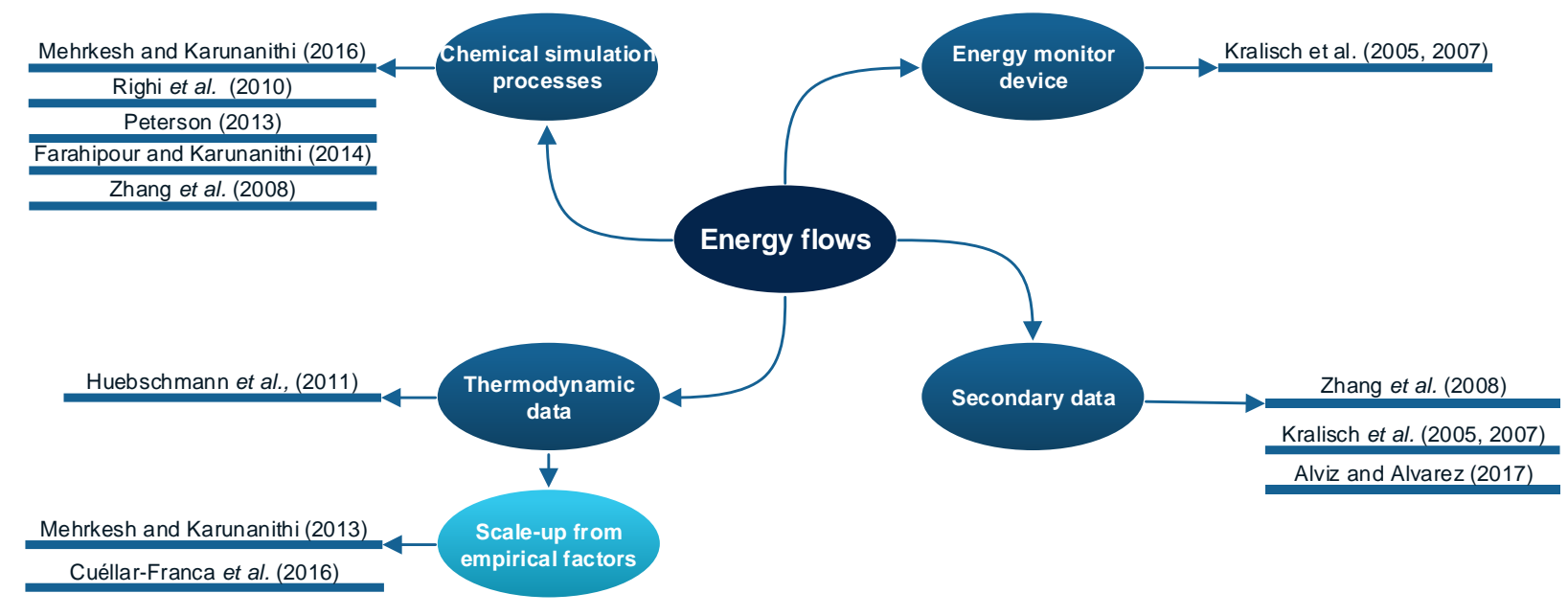

Figure 5. Main approaches employed to determine energy flows

$\mathrm{E}_{\mathrm{i}}=\Delta \mathrm{H} \times \mathrm{Fc}$

$\Delta \mathrm{H}=\sum(\mathrm{n} . \widehat{\mathrm{H}})$ outputs $-\sum(\mathrm{n} . \widehat{\mathrm{H}})$ inputs

Eq. 1

$\widehat{\mathrm{H}}=\Delta \widehat{\mathrm{H}}^{\circ}+\int_{\mathrm{T} 1}^{\mathrm{T} 2} \mathrm{Cp} \cdot \Delta \mathrm{T}$

Eq. 2

Eq. 3

where:

$\mathrm{E}_{\mathrm{i}}$ : theoretical energy consumption

$\Delta \mathrm{H}$ : heat of reaction

$\mathrm{n}=$ molecular weight of reactants

$\widehat{H}=$ specific enthalpy of reactants

$\Delta \widehat{H} f^{\circ}=$ heat of formation of reactants

$\mathrm{Cp}=$ calorific value of reactants

$\mathrm{T} 1=$ reference temperature

$\mathrm{T} 2=$ temperature of the reactants

$\mathrm{Fc}=\mathrm{a}$ factor of 4.2 for endothermic reactions with the assumption of natural gas-powered heating and a factor of 3.2 for exothermic reactions with the assumption that cooling uses electricity (Mehrkesh and Karunanithi, 2013).

In some cases the life cycle material and energy consumption data were estimated from chemical process simulation (Righi et al. (2011); Zhang et al. (2008); Mehrkesh and Karunanithi, 
(2016a)). In general, for use of chemical process simulation, it is necessary to have a large amount of available data derived from the combination of energy balances, mass balances, theoretical calculations and secondary data from the literature. In addition, specific data on ILs and intermediate substances could be necessary for conducting a chemical process simulation, for instance, in Huang et al., (2014) some physical-chemistry data necessary for conducting their simulation were shown, i.e. heat capacity, density, viscosity, surface tension, thermal conductivity and scalar property parameters (e.g. molecular mass, acentric factor, normal boiling point, critical pressure and temperature, critical volume and critical compressibility factor) amongst other thermodynamic parameters.

\subsection{Overview of the Life Cycle Inventories}

The results of the criteria applied in this study for the life cycle inventory analysis are highlighted in Table 5. In this review, four aspects are identified as key issues that strongly affect the completeness of the LCA studies: (i) yield of reaction, (ii) reuse, (iii) recycling and (iv) final disposal (see Figure 6). The principle of completeness is to account for all inputs and outputs for the functional unit and within the chosen inventory boundary (Kralisch et al., 2015). Only six of the analysed studies reported definite numbers for input flow and/or output flow, including quantitative LCI information reported in publications: in tables, flow diagrams and/or supporting materials (Zhang et al. (2008), Cuéllar-Franca et al., (2016), Mehrkesh and Karunanithi, (2013), Righi et al., (2011), Alviz and Alvarez, (2017)). In terms of the input, all studies covered in detail the energy inputs and, also in many of the studies, the material inputs; whilst for many of the studies assessed, the output side was less well described. Only two studies partially covered all aspects of the processes; the IL-based carbon capture study by CuéllarFranca et al., (2016) and the study focussed on aquatic ecotoxicity impacts of ILs by Mehrkesh and Karunanithi, (2016a). 
Table 5. Summary of criteria applied in this study for life cycle inventory analysis (completeness of studies)

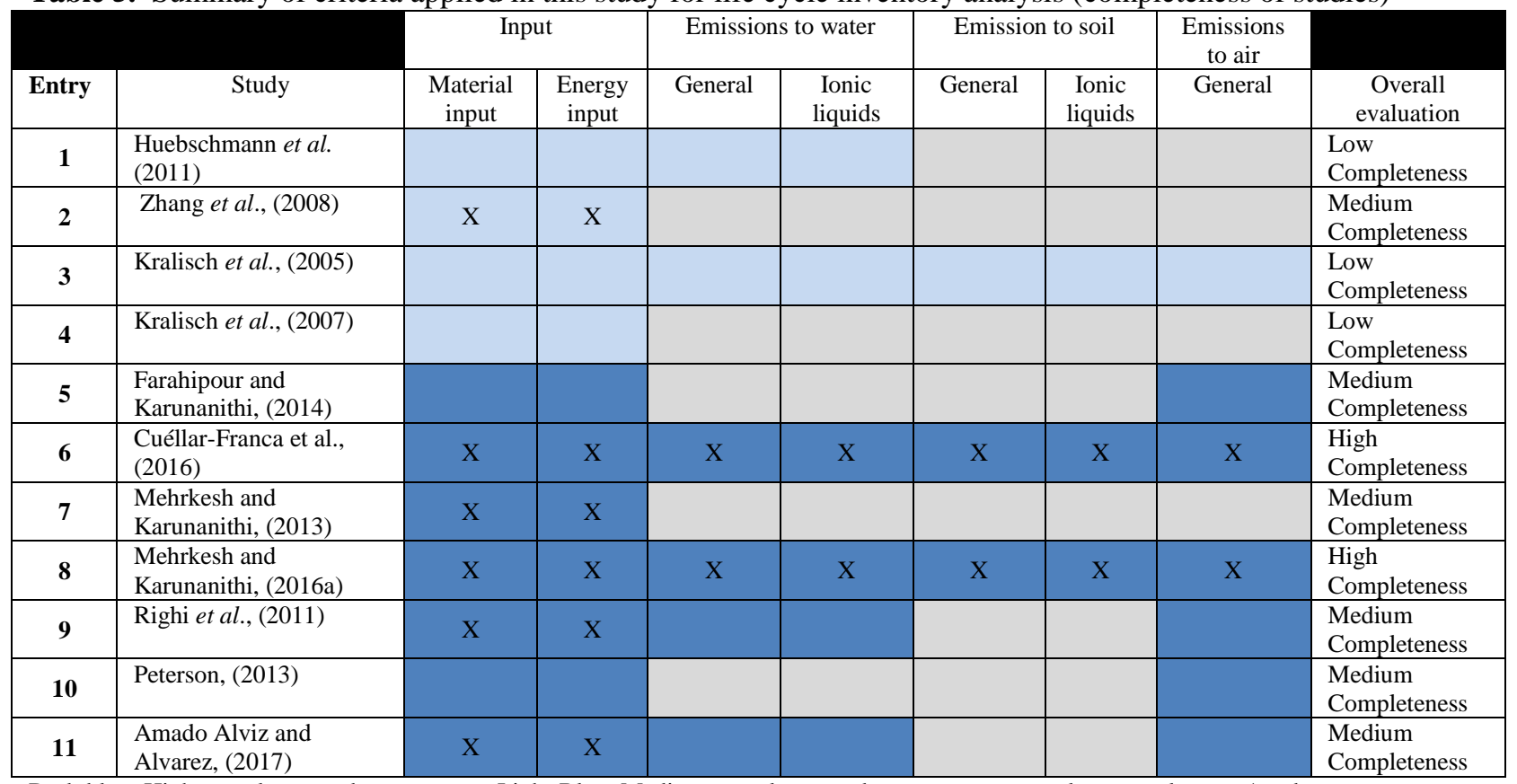

Dark blue: High completeness data coverage; Light Blue: Medium completeness data coverage; grey: low completeness/no data coverage or no information given; marked with " $x$ ": quantitative LCI information was reported in study (inclusive of supporting materials). General: Emission from other chemical substances that are not ionic liquids. Notes: Criteria weight scale: Low to Medium and then High. Low $=$ Incomplete data or no filling of data gaps. Medium = Incomplete data, gaps filled with qualified assumptions. High = Comprehensive data including information about energies, masses and by-products.

In order to obtain high completeness during LCI, every energy and mass and flow that is within the study scope should be documented (Kralisch et al., 2015). The yield of a chemical reaction is an important process parameter, as it determines the amount of substrate required (Piccinno et al., 2016; Tufvesson et al., 2013). According to Tufvesson et al., (2013), the entire environmental performance of a product can be greatly improved by a high yielding reaction, because up to $90 \%$ of the entire environmental impact is due to raw material production. 


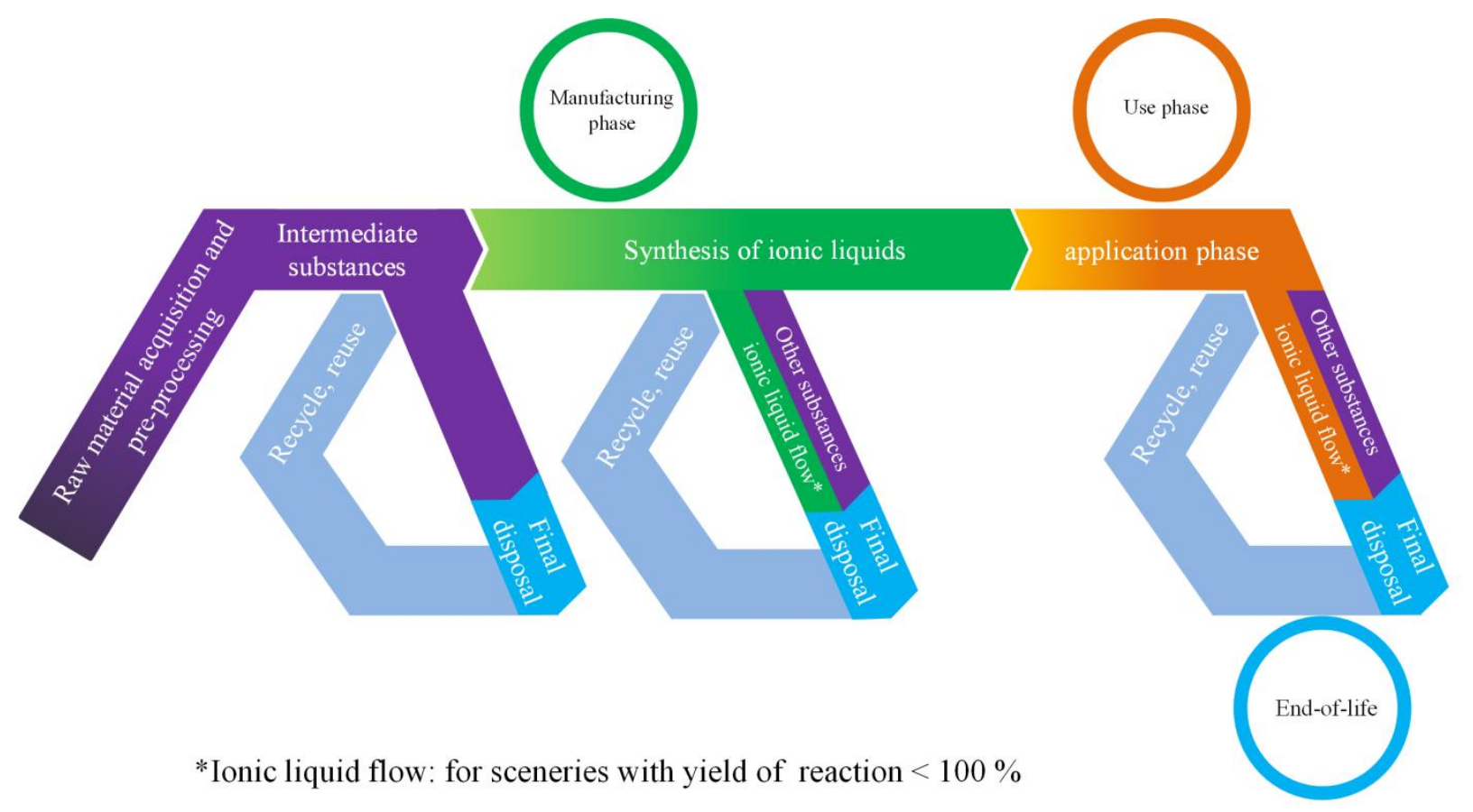

Figure 6.Schematic representation of life cycle perspective of Ionic liquids

The reuse, recycling or final disposal of ionic liquids are important parameters associated with the completeness of studies. Overall, the final disposal of ionic liquids has not been thoroughly reported in the literature thus far. One study treated the disposal of the ionic liquid as 'disposal of organic waste' (Huebschmann et al., 2011), and in another work, only the transport to final disposal was assumed (Peterson, 2013). However, many methods for the recycling and reuse of ionic liquids have been researched. The most explored options include extraction, adsorption, use of supercritical $\mathrm{CO}_{2}$, and also membrane separation processes (Mai et al., 2014). Furthermore, a distillation method using a membrane to separate water from the ILs that were used for biomass pre-treatment was reported by Lynam et al., (2016).

Previous studies have shown the importance of IL reuse, especially when employed as a solvent (Amado Alviz and Alvarez, 2017; Farahipour and Karunanithi, 2014; Huebschmann et al., 2011; Zhang et al., 2008). It has been found that recovery of the solvent is an important parameter that may make the utilization of ILs an alternative comparable to the use of toluene for production of acetylsalicylic acid (Alviz and Alvarez, (2017)). The influence of solvent recovery was evaluated using sensitivity analysis assuming recovery rates in the range of 89 to $98 \%$. Sensitivity analysis was also used by Zhang et al., (2008) to evaluate the impact of the number of times an IL was 
reused, by considering recycling from 5 to 20 times. Furthermore, Zhang et al., (2008) showed that even with a recycling of the ionic liquid 20 times, conventional processes for the production of cyclohexane still had a smaller life cycle impact than the process that utilized an ionic liquid for the production of cyclohexane. In contrast, Farahipour and Karunanithi, (2014) and Peterson, (2013) assumed no loss or degradation with complete reuse of ILs. In this case, the authors assumed that the impacts of the extraction, synthesis, and transport of the raw substrates, synthesis of ionic liquids and end-of-life are neglected, due to reuse of the ionic liquid. 


\section{LIFE CYCLE IMPACT ASSESSMENT STEP}

This section presents the impact categories and characterization methods employed in the studies reviewed in this paper (Table 7). The results of the criteria applied in this study for the life cycle impact assessment steps are highlighted in Table 9. The life cycle impact assessment methods define the environmental impact categories based on characterization factors. In turn, these factors are further expanded by considering the inherent properties of chemicals (e.g., toxicity), in addition to information on the transport and potential mode of exposure (Mehrkesh and Karunanithi, 2013). Twenty different impact categories were considered in the studies assessed in this review. From those, only five impacts categories are common to at least $70 \%$ of the studies; eutrophication, acidification, ozone depletion, global warming and human toxicity. Furthermore, there were few studies that reported complete LCA results, and it must be noted that these results are very important for future comparison. Table $\mathbf{7}$ shows the there is a lack of information of the methods of characterization of impacts applied for each study evaluated in this work. CML 2001 Method (PRé Consultants, 2014) was determined to be the most preferable LCIA method assumed. The employment of this method or a superior one (e.g. CML 2002+ Method) in future studies has been highly recommended (Jolliet et al., 2003). In some studies, the method employed is not clear or is not mentioned, therefore, in these cases, it was assumed as not available for that work. 
Table 6. Categories impacts used for studies.

\begin{tabular}{|c|c|c|c|c|c|c|c|c|c|c|c|}
\hline \multirow[b]{2}{*}{ Impact categories } & \multicolumn{11}{|c|}{ Reference number (see table notes) } \\
\hline & 1 & 2 & 3 & 4 & 5 & 6 & 7 & 8 & 9 & 10 & 11 \\
\hline Abiotic resource & yes & yes & no & yes & no & yes & no & no & yes & no & yes \\
\hline Acidification & yes & yes & no & yes & yes & yes & yes & no & yes & yes & yes \\
\hline Ecotoxicity & no & no & no & no & yes & no & yes & no & yes & yes & no \\
\hline Eutrophication & yes & yes & no & yes & yes & yes & yes & no & yes & no & yes \\
\hline $\begin{array}{l}\text { Fresh water aquatic } \\
\text { ecotoxicity potential }\end{array}$ & yes & yes & no & yes & no & yes & no & yes & yes & no & yes \\
\hline $\begin{array}{l}\text { Fresh water sedimental } \\
\text { ecotoxicity potential }\end{array}$ & yes & no & yes & no & no & no & no & no & no & no & no \\
\hline Global warming & yes & yes & no & yes & yes & yes & yes & no & yes & yes & yes \\
\hline High-NOx POCP & yes & no & no & no & no & no & no & no & no & no & no \\
\hline Human health cancer & no & no & no & no & yes & no & yes & no & no & no & no \\
\hline Human health criteria & no & no & no & no & yes & no & yes & no & no & no & no \\
\hline Human health non-cancer & no & no & no & no & yes & no & yes & no & no & no & no \\
\hline Human toxicity & yes & yes & yes & yes & no & yes & no & no & yes & no & yes \\
\hline Land use & yes & no & no & no & no & no & no & no & no & no & no \\
\hline Low - NOx POCP & yes & no & no & no & no & no & no & no & no & no & no \\
\hline Marine sedimental ecotoxicity & yes & yes & yes & yes & no & yes & no & no & no & no & no \\
\hline Ozone depletion & yes & yes & no & yes & no & yes & no & no & yes & no & Yes \\
\hline Photochemical oxidation & no & yes & no & yes & no & yes & no & no & yes & no & No \\
\hline Smog & no & no & no & no & yes & no & yes & no & no & yes & No \\
\hline $\begin{array}{l}\text { Terrestrial ecotoxicity } \\
\text { potential* }\end{array}$ & yes & yes & no & no & no & yes & no & no & yes & no & Yes \\
\hline VOC emissions & no & yes & no & no & no & no & no & no & yes & no & No \\
\hline Energy demand & yes & no & yes & yes & no & no & no & no & no & no & No \\
\hline Dichlorobenzene & no & no & no & no & no & yes & no & no & no & no & No \\
\hline Cost & yes & no & yes & no & no & no & no & no & no & no & No \\
\hline
\end{tabular}


Table 7. Life cycle assessment methods of characterization used in the previous studies.

\begin{tabular}{|c|c|c|}
\hline Entry & Study & LCA method of characterization \\
\hline 1 & Huebschmann et al. (2011) & CML 2001 and CED \\
\hline 2 & Zhang et al., (2008) & N/A \\
\hline 3 & Kralisch et al., (2005) & CED \\
\hline 4 & Kralisch et al., (2007) & CED and another \\
\hline 5 & Farahipour and Karunanithi, (2014) & TRACI \\
\hline 6 & Cuéllar-Franca et al., (2016) & CML 2001 \\
\hline 7 & Mehrkesh and Karunanithi, (2013) & TRACI \\
\hline 8 & Mehrkesh and Karunanithi, (2016a) & USEtox-Based \\
\hline 9 & Righi et al., (2011) & CML 2001 \\
\hline 10 & Peterson, (2013) & $\mathrm{N} / \mathrm{A}$ \\
\hline 11 & Amado Alviz and Alvarez, (2017) & CML 2001 \\
\hline \multicolumn{3}{|c|}{$\begin{array}{l}\text { N/A: Not available; CED: Cumulative Energy Demand V1.09 method (PRé Consultants, 2014); TRACI: TRACI Method (the "Tool for } \\
\text { Reduction and Assessment of Chemical and other Environmental Impacts") by the U.S. EPA (Bare, 2008); CML 2001: CML } 2001 \text { method by } \\
\text { Institute of Environmental Sciences (PRé Consultants, 2014); USEtox-Based effect factors for the ionic liquids [Bmim][Br], [Bmim][Cl], } \\
\text { [Bmim][BF }] \text {, [Bmim][PF6], and [BPy][Cl] were made and used (Kadziński et al., 2016). }\end{array}$} \\
\hline
\end{tabular}

In general, a common limitation in the entirety of the studies listed above is that consideration of any possible impacts associated with final disposal of ionic liquids, as well as toxicity was not given (Mehrkesh and Karunanithi, 2016a). Indeed, some studies have reported that ionic liquids present some toxicity to aquatic organisms (Heckenbach et al., 2016; Thuy Pham et al., 2010). On the contrary, ionic liquid toxicity information has not been included in LCA studies to date, due to the scarcity of toxicity-based characterization factors for ionic liquids. Recently, Mehrkesh and Karunanithi, (2016a) have proposed freshwater ecotoxicity characterization factors for a set of five ionic liquids (Table 9). In that study, the USEtox model, an up-to-date modeling framework built on scientific consensus for characterization of human and ecotoxicological impacts of chemicals (Rosenbaum et al., 2008), was utilized to develop characterization factors. All the evidence indicates that ionic liquids emissions in freshwater may cause damage to the ecosystem, and thus of inclusion of those impacts into boundary system could lead to modification of LCA results. 
Table 8.Characterization factors for freshwater ecotoxicity of some common ionic liquids

\begin{tabular}{|c|c|}
\hline Ionic Liquid & Characterization factors (CTUe / kg) \\
\hline$[$ Bmim $][\mathbf{B r}]$ & 624 \\
\hline$[$ Bmim $][\mathbf{C l}]$ & 748 \\
\hline$[$ Bmim $]\left[\mathrm{BF}_{4}\right]$ & 823 \\
\hline$[$ Bmim $]\left[\mathbf{P F}_{6}\right]$ & 927 \\
\hline$[$ BPy $][\mathbf{C l}]$ & 1768 \\
\hline
\end{tabular}

Source: Mehrkesh and Karunanithi, (2016a); CTUe: Comparative Toxic Unit

In this review, it is not fully possible to afford a full comparison of the environmental impact results of the studies highlighted, as the goals and scopes, inventory completeness, methods of characterization applied and impact categories of these studies greatly differ. However, there are some previous studies that compared the environmental performance of some ionic liquids, such as butylmethylimidazoluim chloride [Bmim][Cl], (Amado Alviz and Alvarez, 2017; Righi et al., 2011) and trihexyltetradecylphosphonium 1,2,4-triazolide ([P $\left.{ }_{66614}\right][124$ Triz] $)$ (Cuéllar-Franca et al., 2016). These studies reported Global Warming Potential (GWP) impacts estimated at $6.30 \mathrm{~kg}$ $\mathrm{CO}_{2}$ eq. per $\mathrm{kg}$ of $\left[\mathrm{P}_{66614}\right][124 \mathrm{Triz}]$ and $6.40 \mathrm{~kg} \mathrm{CO} 2$ per $\mathrm{kg}$ of $[\mathrm{Bmim}][\mathrm{Cl}]$. Also, Huebschmann et al. (2011) reported large differences between the environmental performances of ionic liquids using life cycle methodology. In their study, [Bmim][Cl] showed GWP impacts five times smaller than 1-octadecyl-3-methylimidazolium bromide ([ $\left.\left.\mathrm{C}_{18} \mathrm{MIM}\right][\mathrm{Br}]\right)$ (Huebschmann et al., 2011).

Table 9. Results of criteria applied in this study for life cycle assessment

\begin{tabular}{|c|c|c|c|}
\hline Entry & Reference & $\begin{array}{l}\text { Assessment } \\
\text { Result }\end{array}$ & Justification \\
\hline 1 & $\begin{array}{l}\text { Huebschmann et al. } \\
\text { (2011) }\end{array}$ & Medium & Impact categories were partially justified \\
\hline 2 & Zhang et al., (2008) & Low & Characterization methods not clearly defined and justified \\
\hline 3 & Kralisch et al., (2005) & Medium & Characterization method partially defined and justified \\
\hline 4 & Kralisch et al., (2007) & Medium & Characterization method partially defined and justified \\
\hline 5 & $\begin{array}{l}\text { Farahipour and } \\
\text { Karunanithi, (2014) }\end{array}$ & High & $\begin{array}{l}\text { Covered more than one impact category, also impact } \\
\text { categories and characterization methods clearly defined and } \\
\text { justified }\end{array}$ \\
\hline 6 & $\begin{array}{l}\text { Cuéllar-Franca et al., } \\
\text { (2016) }\end{array}$ & High & $\begin{array}{l}\text { Covered multiple impact categories, also impact categories } \\
\text { and characterization methods clearly defined and justified }\end{array}$ \\
\hline 7 & $\begin{array}{l}\text { Mehrkesh and } \\
\text { Karunanithi, (2013) }\end{array}$ & High & $\begin{array}{l}\text { Covered multiple impact categories, also impact categories } \\
\text { and characterization methods clearly defined and justified }\end{array}$ \\
\hline 8 & $\begin{array}{l}\text { Mehrkesh and } \\
\text { Karunanithi, (2016a) }\end{array}$ & Medium & One impact category evaluated \\
\hline
\end{tabular}




\begin{tabular}{|c|c|c|c|}
\hline 9 & Righi et al., (2011) & High & $\begin{array}{l}\text { Covered more than one impact category, also impact } \\
\text { categories and characterization methods clearly defined and } \\
\text { justified }\end{array}$ \\
\hline 10 & Peterson, (2013) & Low & Characterization methods not defined and justified \\
\hline 11 & $\begin{array}{l}\text { Amado Alviz and } \\
\text { Alvarez, (2017) }\end{array}$ & High & $\begin{array}{l}\text { Covered more than one impact category, also impact } \\
\text { categories and characterization methods clearly defined and } \\
\text { justified }\end{array}$ \\
\hline
\end{tabular}




\section{LCA INTERPRETATION}

According to ISO 14044, the interpretation step consists of three approaches; (i) identification of a significant issue, analysis of the results, comparisons and hot-spots, (ii) evaluation and (iii) conclusions. The first step is mostly performed by building the results of the LCI and LCIA (de Bruijn et al., 2002). The evaluation step deals with how complete a database may be, the indication of data quality and the sensitivity analysis of the results due to data changes. Kralisch et al., (2015) have checked these criteria, conclusions (step iii) can be made concerning the resultant recommendations based on analysis of the results and comparison, identify opportunities for improvements and also identify the limitations of the LCA study (de Bruijn et al., 2002; Kralisch et al., 2015)

As highlighted above, the inventory database involving ILs are scarce and often different methods and sources of data are needed for building them. Therefore, the data quality depends on the sources that were available for the particular study (Kralisch et al., 2015). A common procedure in the literature to indicate the quality of the data in an LCA is known as the 'Pedigree Matrix', which was developed for this purpose of indicating data quality by Weidema and Wesnaes, (1996). The indicators of data quality utilized by Weidema and Wesnaes, (1996) is scored (1 to 5, where 1 is best and 5 is worst) on the following independent data quality characteristics; (i) Completeness (statistical representativeness of the data and the periods of time for data collection); (ii) temporal correlation, (iii) geographic correlation, (iv) further technological and (v) reliability (sampling methods and verification procedures).

None of the studies highlighted in this review performed the data quality analysis on the data of the LCI data, thus are being considered as 'Low'. The necessity for large amount of information on the LCI data, and time expenditure for conducting this analysis are some of the reason why it was not applied. In this context, Kralisch et al., (2015) proposed a 'modified Pedigree Matrix' applicable to indication of data quality in the context of design of chemical processes and syntheses, where the following quality indicators are used; completeness, representativeness, and reliability. One significant difference between the well-established Weidema valuation system and the system proposed by Kralisch et al. is the aggregation of the time, space and technological correspondence 
indicators into one indicator named 'representativeness'. For the interested reader, more discussion about analysis of data quality and recommendations on analysis of data quality can be found in the works of Weidema and Wesnaes, (1996) and Kralisch et al.,(2015).

Therefore, the indicators of data quality derived from the use of the "Pedigree Matrix" is a tool for data quality management (Muller et al., 2016) and is recommended for analysis of data quality in life cycle studies (de Bruijn et al., 2002). Hence, considering the state-of-art of the LCI of ILs it is recommended that it is essential to incorporate data quality indicators. 


\section{RECOMMENDATIONS TO OVERCOME EXISTING GAPS}

Several limitations associated with implementation of the LCA in all its steps to ILs have been identified in this review. However, the major limitations occur due to the absence of LCIs and characterisation factors, thus these should be the focus of future LCA studies on ILs to improve the knowledge on the environmental performance of the life cycle of ILs. The LCI step is the critical phase of LCA that corresponds to the accumulation and quantification of system inputs and output data. Hence, different methods for building LCIs may afford differing results in terms of environmental impact for the same process or product (Islam et al., 2016). Thus, the current lack of complete data complicates the task. It is a fact that, in terms of impact assessment, it is important to have sufficient LCI data in order to be able to take account of the material in a more appropriate manner to support the decision making of the LCA practitioner (Hischier and Walser, 2012). In other words, it was identified that:

i) inventory database of ILs synthesis, application phase and final disposal with a high degree of representativeness and completeness are needed;

ii) better information on separation efficiencies, recovery and amounts of reuse is needed;

iii) potential environmental impacts associated with direct environmental release of ionic liquids were not considered in the studies;

iv) efficiency of reaction (yield of reaction) of ionic liquid synthesis should be considered;

v) use of data quality indicators for the analysis of data into LCI.

To enable a choice of a particular approach to build LCIs, the calculation technique and relative limitations and advantages for the purpose should be known. Hence, the choice of the approaches used for building LCIs firstly should consider the goal and scope of the specific study. Also, it is recommended to consider the data requirements, availability of data and the associated time expenditure. In Figure 7 the relationship between the need for data and the ease of applying it for each approach is illustrated. 


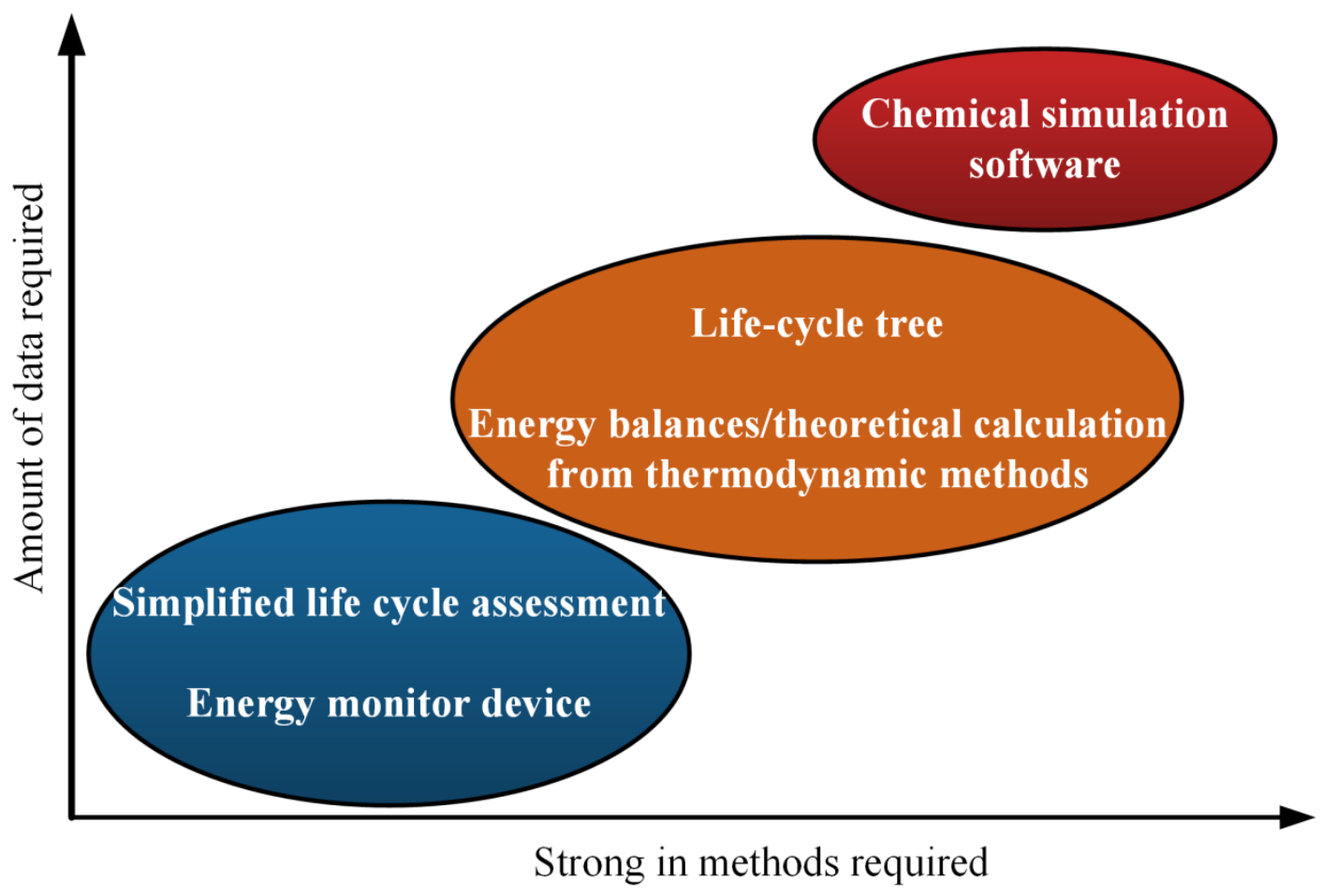

Figure 7. Illustration of the relationship between the need for data and the ease of applying it for each approach

In this review, the life-cycle tree approach is recommended for the LCA of emergent chemical substances, such as ILs, which normally have complex structures involving many precursors for which inventory databases are scarce or unavailable. This approach can be applied in a first screening of the life cycle of ILs, and it can also be useful for supporting of chemical simulations.

The lack of industrial data involving the manufacture of IL has been identified as a current limitation for applying LCA studies on ILs, mainly data associated with energy demanded for manufacturing of ILs and their precursors. However, the impact of this limitation can be minimized by using the following methods: chemical simulation software, empirical factors as proposed in Mehrkesh and Karunanithi, (2013) or other methods reported in literature. For example, the scale up of chemical synthesis process for life cycle assessment studies using only laboratory scale experimental data can be achieved through of the framework reported by Piccinno et al., (2016). 
To improve the completeness of LCA studies an important factor that needs to be determined when building the LCI of a chemical substance is the efficiency of reaction (yield of reaction). Indeed, several studies have reported the influence of yield on LCA results (Huebschmann et al., 2011; Kralisch et al., 2015, 2007; Sell et al., 2014; Zhang et al., 2008). The amounts of byproducts and unreacted materials are calculated from the known reaction conversion rate and product yield of the reaction. Therefore, for small conversion rates more supplies are demanded and more waste is generated, consequently the environmental impact increases. Often the functional unit (as defined above) assumed has a relationship with the number of ionic liquids synthesised or with the reaction assessed, hence it is expected that the efficiency of reaction has influence on the LCA results. Primary source data of yield rates are recommended, e.g. data from industrial plants, pilot scales, laboratory scales or data from literature based on experimental results. The yield can be theoretically assumed to $100 \%$ when data is not available, but it is recommended to assume lesser amount. For instance in Hischier et al. (2005) the yield assumed was $95 \%$. For these assumptions, the use of sensitivity analysis for assessment of the effect of each variable on LCA result, is recommended.

Regarding the interpretation step, the analysis of data quality has not been applied in the studies reviewed herein. The employment of methods for analysing data quality is useful, mainly due to the characteristics of emerging substances, such as ILs, which have inventory database built using different methods and sources. Thus, the method proposed by Weidema and Wesnaes, (1996), and more recently the simplified method by Kralisch et al., (2015) for applying data quality indicators, should be considered in future LCA studies with ILs. Several studies have tested the robustness of the results obtained through use of a combination of methods for material and energy balances by applying sensitivity and uncertainty analyses (Cuéllar-Franca et al., 2016; Huebschmann et al., 2011; Kralisch et al., 2015; Zhang et al., 2008). Sensitivity analysis is a practical tool for evaluating how robust results are and for determining the sensitivity of the results to particular factors in the LCA (Kralisch et al., 2015). Thus, these practices are highly recommended and should be applied when the data are estimated and/or there is a lack of information. 
Finally, for the characterisation factors related to ILs, the initial question that needs to be answered is "Which environmental organisms and compartments are affected, to what extent, and by which particular characteristics of the ionic liquids?" According to Mehrkesh and Karunanithi, (2016b) the intermediate transference and spread of chemical compounds between differing environmental compartments are modelled as an array of mass balance equations, assuming equilibrium conditions. However, knowledge about these methods and application of these methods to ILs currently is scarce and must be the focus of future studies. 


\section{CONCLUSIONS}

This review has provided a summary of current environmental life cycle assessment case studies on ionic liquids (ILs), and also has identified the existing shortcomings that are delaying the analysis of ionic liquid based processes with the life cycle assessment framework. Previous studies have reported large environmental impacts when ionic liquid life cycles were considered. Thus, the utilization of life cycle assessment to ionic liquids has been instrumental to the recognition of the real environmental impacts of these emergent substances. However, its use has not kept up with the fast development of these new substances and the ionic liquids field.

Overall, the number of available LCAs of ionic liquids in the literature is limited when compared with the number of ILs which can be made or have been used ( $c f$. Figure 1). Furthermore, the largest type of ILs analysed are based on the butylmethylimidazolium cation $\left([\mathrm{Bmim}]^{+}\right)$. In the eleven LCA studies on ionic liquids reviewed in this work, various life-cycle approaches (from gate-to-gate, cradle-to-gate, and cradle-to-crave) and impact assessment approaches have been used, depending on the definite questions to be answered with the analysis. However, cradle-togate was the approach mainly used, and CML 2001 (PRé Consultants, 2014) was determined to be the preferred LCIA method. Eutrophication, acidification, ozone depletion, global warming and human toxicity were common impact categories reported among the studies.

The necessary features of the life cycle assessment methodology were reviewed and several particular limitations in the application of LCA have been established and reviewed. These include the lack of information involving the background processes, mainly for building inventory of IL precursors, how system boundaries and product systems are defined, the quality of data, and there are few characterisation factors for IL.

A set of issues that need to be more precise for application of LCA to evaluate IL processes has been proposed. These issues are; access to complete and sufficient life cycle inventory data during the phase of inventory analysis, and the growth and subsequent inclusion of characterization factors for the impacts of ILs during the impact assessment phase. Also, a 
limitation in every study evaluated is that potential impacts arising from the environmental release of ionic liquids were not considered.

Thus, some practices are recommended in LCA of ILs, such as: to use approach that considers life cycle phases (using life cycle-tree for building LCIs is recommended), to consider reuse and recycle of the ILs and to consider the yield of reaction involving ILs and intermediate substances. Different studies adopt different methods of LCI, also a series of assumptions and approaches were used to estimate them. For this reason, the employment of data quality analysis is essential and should be included for building LCI of ILs. Furthermore, the robustness of the results needs to be examined by use of uncertainty and sensitivity analyses.

Besides that, the scarcity of the characterisation factors of IL for human toxicity and ecotoxicity impact categories halts inclusion in the LCIA. Therefore, a comprehensive LCIA for a chemical process that involves ILs will only be achievable when the characterisation factors of the IL are fully available.

Therefore, to improve the present situation, it is important to improve each of the steps of the LCA to the extent allowed by scientific advances. This review demonstrates new advances to decrease the gaps in LCIs and the characterised factors that will be the focus of future studies on application of LCA to IL processes. Indeed, it should be noted that the authors very recently published a LCA study on the environmental performance of 3D-printing ionic liquids, which incorporates the recommended practices highlighted in this review (Maciel et al., 2018). 


\section{ABBREVIATIONS}

1-butyl-3-methyl-imidazolium tetrafluoroborate $\left(\left[\mathrm{Bmim}^{-}\left[\mathrm{BF}_{4}\right]\right)\right.$

1-alkyl-3-methylimidazolium chloride $\left(\left[\mathrm{C}_{4} \mathrm{mim}\right] \mathrm{Cl}\right)$

n-hexylpyridinium chloride $\left(\left[\mathrm{C}_{6} \mathrm{Py}\right][\mathrm{Cl}]\right)$

1-hexyl-3-methylimidazolium chloride ([C 6 MIM] [Cl])

1-butyl-3-methylimidazolium acetate ([Bmim][Ac])

trihexyltetradecylphosphonium 1,2,4-triazolide ([P $\left.\mathrm{P}_{6614}\right]$ [124Triz])

1- butyl-3-methylimidazolium bromide ([Bmim][Br])

1-butyl 3-methylimidazolium chloride ([Bmim] [Cl])

1-butyl 3- methylimidazolium tetrafluoroborate $\left([\mathrm{Bmim}]\left[\mathrm{BF}_{4}\right]\right)$

1- butyl-3-methylimidazolium hexafluorophosphate ([Bmim] $\left.\left[\mathrm{PF}_{6}\right]\right)$

1-butylpyridinium chloride $([\mathrm{BPy}][\mathrm{Cl}])$

1-hexyl-3-methylimidazolium bis(trifluoromethylsulfonyl)imide ([hmim][TNf 2$])$

trihexyl(tetradecyl)phosphonium 1,2,3-triazolide ([ $\left.\mathrm{P}_{66614}\right]$ [3triazolide])

1-octadecyl-3-methylimidazolium bromide ([C $\left.\left.{ }_{18} \mathrm{MIM}\right][\mathrm{Br}]\right)$

1-butyl-3-methylimidazolium bis(trifluoromethane)sulfonimide ([Bmim] $\left.\left.\mathrm{NTf}_{2}\right]\right)$ 


\section{ACKNOWLEDGMENTS}

V.G-M. and M.S. wish to thank the Brazilian Government by National Council for the Improvement of Higher Education (CAPES) support and the University of Nottingham is

gratefully acknowledged for funding. This study was financed in part by the Coordenação de Aperfeiçoamento de Pessoal de Nível Superior - Brasil (CAPES) - Finance Code 001. C.M.L-U. wishes to thank the Brazilian Government by National Council of Technological and Scientific Development $(C N P q)$. 


\section{CONFLICTS OF INTEREST}

The authors declare no conflicts of interest. 


\section{REFERENCES}

Amado Alviz, P.L., Alvarez, A.J., 2017. Comparative life cycle assessment of the use of an ionic liquid $([\mathrm{Bmim}] \mathrm{Br})$ versus a volatile organic solvent in the production of acetylsalicylic acid. J. Clean. Prod. 168, 1614-1624. https://doi.org/10.1016/j.jclepro.2017.02.107

ATcT (Active Thermochemical Tables), n.d. Thermochemical Tables [WWW Document]. URL https://atct.anl.gov/

Bare, J.C., 2008. TRACI:The Tool for the Reduction and Assessment of Chemical and Other Environmental Impacts. J. Ind. Ecol. 6, 49-78. https://doi.org/10.1162/108819802766269539

Bernard, F.L., Rodrigues, D.M., Polesso, B.B., Donato, A.J., Seferin, M., Chaban, V. V., Vecchia, F.D., Einloft, S., 2016. New cellulose based ionic compounds as low-cost sorbents for CO2 capture. Fuel Process. Technol. 149, 131-138. https://doi.org/10.1016/J.FUPROC.2016.04.014

Cerdas, F., Juraschek, M., Thiede, S., Herrmann, C., 2017. Life Cycle Assessment of 3D Printed Products in a Distributed Manufacturing System. J. Ind. Ecol. 21, S80-S93. https://doi.org/10.1111/jiec.12618

Cuéllar-Franca, R.M., García-Gutiérrez, P., Taylor, S.F.R., Hardacre, C., Azapagic, A., 2016. A novel methodology for assessing the environmental sustainability of ionic liquids used for CO2 capture. Faraday Discuss. 192, 283-301. https://doi.org/10.1039/C6FD00054A

D’Alessandro, D.M., Smit, B., Long, J.R., 2010. Carbon dioxide capture: Prospects for new materials. Angew. Chemie - Int. Ed. 49, 6058-6082. https://doi.org/10.1002/anie.201000431

de Bruijn, H., Duin, R. van, Huijbregts, M.A.J., 2002. Handbook on Life Cycle Assessment, Operational Guide to the ISO Standards. Kluwer Academic Publishers, USA. https://doi.org/10.1007/0-306-48055-7

DETHERM, 2017. thermophysical property data [WWW Document]. DETHERM - Soc. Chem. Eng. Biotechnol.

Disasa Irge, D., 2016. Ionic Liquids: A Review on Greener Chemistry Applications, Quality Ionic Liquid Synthesis and Economical Viability in a Chemical Processes. Am. J. Phys. Chem. 5, 74. https://doi.org/10.11648/j.ajpc.20160503.14 
Dong, L.L., He, L., Tao, G.H., Huang, M., Hu, C., 2013. Theoretical enthalpies of formation of [AA]X and [AAE]X type amino acid ionic liquids. J. Chem. Eng. Data 58, 1176-1185. https://doi.org/10.1021/je301285c

Dunn, M.H., Cole, M.L., Harper, J.B., 2012. Effects of an ionic liquid solvent on the synthesis of $\gamma$-butyrolactones by conjugate addition using NHC organocatalysts. RSC Adv. 2, 10160. https://doi.org/10.1039/c2ra21889e

Farahipour, R., Karunanithi, A., 2014. Life Cycle Environmental Implications of CO2 Capture and Sequestration with Ionic Liquid 1-butyl-3-methylimidazolium acetate. ACS Sustain. Chem. Eng. 2, 2495-2500. https://doi.org/10.1021/sc400274b

Felder, R.M., Rousseau, R.W., 2005. Elementary Principes of Chemical Processes, 3rd ed. John Wiley \& Sons, Inc., USA.

Frischknecht, R., 1998. Life cycle Inventory Analysis for decision-making. Swiss Federal Institute of Technology Zurich.

Ghandi, K., 2014. A Review of Ionic Liquids, Their Limits and Applications. Green Sustain. Chem. 4, 44-53. https://doi.org/10.4236/gsc.2014.41008

Hagiwara, R., Lee, J.S., 2007. Ionic Liquids for Electrochemical Devices. Electrochemistry 75, 23-34. https://doi.org/10.5796/electrochemistry.75.23

Heckenbach, M.E., Romero, F.N., Green, M.D., Halden, R.U., 2016. Meta-analysis of ionic liquid literature and toxicology. Chemosphere 150, 266-274. https://doi.org/10.1016/j.chemosphere.2016.02.029

Hischier, R., Hellweg, S., Capello, C., Primas, A., 2005. Establishing life cycle inventories of chemicals based on differing data availability. Int. J. Life Cycle Assess. 10, 59-67. https://doi.org/10.1065/lca2004.10.181.7

Hischier, R., Walser, T., 2012. Life cycle assessment of engineered nanomaterials: State of the art and strategies to overcome existing gaps. Sci. Total Environ. 425, 271-282. https://doi.org/10.1016/j.scitotenv.2012.03.001

Huang, Y., Zhang, X., Zhang, X., Dong, H., Zhang, S., 2014. Thermodynamic Modeling and Assessment of Ionic Liquid-Based $\mathrm{CO}_{2}$ Capture Processes. Ind. Eng. Chem. Res. 53, 11805-11817. https://doi.org/10.1021/ie501538e

Huebschmann, S., Kralisch, D., Loewe, H., Breuch, D., Petersen, J.H., Dietrich, T., Scholz, R., 2011. Decision support towards agile eco-design of microreaction processes by 
accompanying (simplified) life cycle assessment. Green Chem. 13, 1694. https://doi.org/10.1039/c1gc15054e

Islam, S., Ponnambalam, S.G., Lam, H.L., 2016. Review on life cycle inventory: methods, $\begin{array}{lllll}\text { examples and } & \text { applications. J. Clean. Prod. }\end{array}$ https://doi.org/http://dx.doi.org/10.1016/j.jclepro.2016.05.144

ISO 14040, 2006. Environmental management - Life Cycle Assessment - Principles and Framework, International Organization for Standardization. https://doi.org/10.1016/j.ecolind.2011.01.007

ISO 14044, 2006. Environmental management - Life cycle assessment - Requirements and guidelines, International Organization for Standardization.

Jacquemin, L., Pontalier, P.-Y., Sablayrolles, C., 2012. Life cycle assessment (LCA) applied to the process industry: a review. Int. J. Life Cycle Assess. 17, 1028-1041. https://doi.org/10.1007/s11367-012-0432-9

Jolliet, O., Margni, M., Charles, R., Humbert, S., Payet, J., Rebitzer, G., 2003. Presenting a New Method IMPACT 2002 +: A New Life Cycle Impact Assessment Methodology. Int. J. Life Cycle Assesment 8, 324-330. https://doi.org/10.1007/BF02978505

Kadziński, M., Cinelli, M., Ciomek, K., Coles, S.R., Nadagouda, M.N., Varma, R.S., Kirwan, K., 2016. Co-constructive development of a green chemistry-based model for the assessment of nanoparticles synthesis. Eur. J. Oper. Res. 0, 1-19. https://doi.org/10.1016/j.ejor.2016.10.019

Karjalainen, E., Wales, D.J., Gunasekera, D.H.A.T., Dupont, J., Licence, P., Wildman, R.D., Sans, V., 2018. Tunable Ionic Control of Polymeric Films for Inkjet Based 3D Printing. ACS Sustain. Chem. Eng. 6, 3984-3991. https://doi.org/10.1021/acssuschemeng.7b04279

Kowsari, E., 2011. Advanced Applications of Ionic Liquids in Polymer Science. Ion. Liq. Appl. Perspect. 3-28. https://doi.org/10.5772/15224

Kralisch, D., Ott, D., Gericke, D., 2015. Rules and benefits of Life Cycle Assessment in green chemical process and synthesis design: a tutorial review. Green Chem. 17, 123-145. https://doi.org/10.1039/C4GC01153H

Kralisch, D., Reinhardt, D., Kreisel, G., 2007. Implementing objectives of sustainability into ionic liquids research and development. Green Chem. 9, 1308. https://doi.org/10.1039/b708721g 
Kralisch, D., Stark, A., Koersten, S., Kreisel, G., Ondruschka, B., 2005. Energetic, environmental and economic balances: Spice up your ionic liquid research efficiency. Green Chem. 7, 301-309. https://doi.org/10.1039/b417167e

Lynam, J.G., Chow, G.I., Coronella, C.J., Hiibel, S.R., 2016. Ionic liquid and water separation by membrane distillation. Chem. Eng. J. 288, 557-561. https://doi.org/10.1016/J.CEJ.2015.12.028

Maciel, V.G., Wales, D.J., Seferin, M., Sans, V., 2018. Environmental performance of 3DPrinting polymerisable ionic liquids. J. Clean. Prod. 214, 29-40. https://doi.org/10.1016/J.JCLEPRO.2018.12.241

Mai, N.L., Ahn, K., Koo, Y.-M., 2014. Methods for recovery of ionic liquids-A review. Process Biochem. 49, 872-881. https://doi.org/10.1016/J.PROCBIO.2014.01.016

Margni, M., Gloria, T., Bare, J., Seppälä, J., Steen, B., Struijs, J., Toffoletto, L., Jolliet, O., 2008. Life Cycle Impact Assessment Programme Guidance on how to move from current practice to recommended practice in Life Cycle Impact Assessment, UNEP/SETAC Life Cycle Initiative.

McCorsley, C., 1981. Process For Shaped Cellulose Article Prepared From A Solution Containing Cellulose Dissolved In A Tertary Amene N-Oxde Solvent. US Patent 4,246,221.

Mehrkesh, A., Karunanithi, A.T., 2016a. Life-Cycle Perspectives on Aquatic Ecotoxicity of Common Ionic Liquids. Environ. Sci. Technol. 50, 6814-6821. https://doi.org/10.1021/acs.est.5b04721

Mehrkesh, A., Karunanithi, A.T., 2016b. Life Cycle Perspectives on Human Health Impacts of Ionic Liquids. bioRxiv 091454-091466. https://doi.org/10.1101/091454

Mehrkesh, A., Karunanithi, A.T., 2013. Energetic ionic materials: How green are they? A comparative life cycle assessment study. ACS Sustain. Chem. Eng. 1, 448-455. https://doi.org/10.1021/sc3001383

Muller, S., Lesage, P., Ciroth, A., Mutel, C., Weidema, B.P., Samson, R., 2016. The application of the pedigree approach to the distributions foreseen in ecoinvent v3. Int. J. Life Cycle Assess. 21, 1327-1337. https://doi.org/10.1007/s11367-014-0759-5

NIST, 2017. NIST Chemistry WebBook [WWW Document]. Natl. Inst. Stand. Technol.

Peterson, J.E., 2013. Ionic Liquid/CO2 Co-Fluid Refrigeration: CO2 Solubility Modeling and Life Cycle Analysis. PhD Thesis, University of Notre Dame. 
Piccinno, F., Hischier, R., Seeger, S., Som, C., 2016. From laboratory to industrial scale: a scaleup framework for chemical processes in life cycle assessment studies. J. Clean. Prod. 135, 1085-1097. https://doi.org/10.1016/j.jclepro.2016.06.164

Plechkova, N. V, Seddon, K.R., 2008. Applications of ionic liquids in the chemical industry. Chem. Soc. Rev. 37, 123-150. https://doi.org/10.1039/b006677j

PRé Consultants, 2014. SimaPro Database Manual - Methods Library. San Francisco.

Righi, S., Morfino, A., Galletti, P., Samorì, C., Tugnoli, A., Stramigioli, C., 2011. Comparative cradle-to-gate life cycle assessments of cellulose dissolution with 1-butyl-3methylimidazolium chloride and N-methyl-morpholine-N-oxide. Green Chem. 13, 367. https://doi.org/10.1039/c0gc00647e

Rosenbaum, R.K., Bachmann, T.M., Jolliet, O., Juraske, R., Koehler, A., Hauschild, M.Z., 2008. USEtox - the UNEP-SETAC toxicity model : recommended characterisation factors for human toxicity and freshwater ecotoxicity in life cycle impact assessment. Int J Life Cycle Assess 13, 532-546. https://doi.org/10.1007/s11367-008-0038-4

Sans, V., Karbass, N., Burguete, M.I., Compañ, V., García-Verdugo, E., Luis, S. V., Pawlak, M., 2011. Polymer-Supported Ionic-Liquid-Like Phases (SILLPs): Transferring Ionic Liquid Properties to Polymeric Matrices. Chem. - A Eur. J. 17, 1894-1906. https://doi.org/10.1002/chem.201001873

Sell, I., Ott, D., Kralisch, D., 2014. Life Cycle Cost Analysis as Decision Support Tool in Chemical Process Development. ChemBioEng Rev. 1, 50-56. https://doi.org/10.1002/cben.201300007

Thuy Pham, T.P., Cho, C.W., Yun, Y.S., 2010. Environmental fate and toxicity of ionic liquids: A review. Water Res. 44, 352-372. https://doi.org/10.1016/j.watres.2009.09.030

Torralba-Calleja, E., Skinner, J., Gutiérrez-Tauste, D., 2013. CO 2 Capture in Ionic Liquids: A Review of Solubilities and Experimental Methods. J. Chem. 473584. https://doi.org/10.1155/2013/473584

Tufvesson, L.M., Tufvesson, P., Woodley, J.M., Börjesson, P., 2013. Life cycle assessment in green chemistry: overview of key parameters and methodological concerns. Int. J. Life Cycle Assess. 18, 431-444. https://doi.org/10.1007/s11367-012-0500-1

Valderrama, J.O., Rojas, R.E., 2009. Critical Properties of Ionic Liquids. Revisited. Ind. Eng. Chem. Res. 48, 6890-6900. https://doi.org/10.1021/ie900250g 
Vatani, A., Mehrpooya, M., Gharagheizi, F., 2007. Prediction of standard enthalpy of formation by a QSPR model. Int. J. Mol. Sci. 8, 407-432. https://doi.org/10.3390/i8050407

Wales, D.J., Cao, Q., Kastner, K., Karjalainen, E., Newton, G.N., Sans, V., 2018. 3D-Printable Photochromic Molecular Materials for Reversible Information Storage. Adv. Mater. 30, 1800159. https://doi.org/10.1002/adma.201800159

Wasserscheid, P., Welton, T. (Eds.), 2008. Ionic liquids in Synthesis. Wiley-VCH Verlag GmbH \& Co. KGaA. https://doi.org/10.1055/s-2003-40869

WBCSD, 2014. Life Cycle Metrics for Chemical Products 120.

Weidema, B., Wesnaes, M., 1996. Data quality management for life cycle inventories-an example of using data quality indicators, Journal of Cleaner Production. https://doi.org/10.1016/S0959-6526(96)00043-1

Yuan, J., Mecerreyes, D., Antonietti, M., 2013. Poly(ionic liquid)s: An update. Prog. Polym. Sci. 38, 1009-1036. https://doi.org/10.1016/j.progpolymsci.2013.04.002

Zhang, X., Zhang, X., Dong, H., Zhao, Z., Zhang, S., Huang, Y., 2012. Carbon capture with ionic liquids: overview and progress. Energy Environ. Sci. 5, 6668. https://doi.org/10.1039/c2ee21152a

Zhang, Y., Bakshi, B.R., Demessie, E.S., 2008. Life cycle assessment of an ionic liquid versus molecular solvents and their applications. Environ. Sci. Technol. 42, 1724-1730. https://doi.org/10.1021/es0713983

Zhu, J.-F., He, L., Zhang, L., Huang, M., Tao, G.-H., 2012. Experimental and theoretical enthalpies of formation of glycine-based sulfate/bisulfate amino acid ionic liquids. J. Phys. Chem. B 116, 113-9. https://doi.org/10.1021/jp209649h

Zhu, S., Chen, R., Wu, Y., Chen, Q., Zhang, X., Yu, Z., 2009. A Mini-Review on Greenness of Ionic Liquids. Chem. Biochem. Eng. Q. 23, 207-211. 